\title{
The Effect of a Simple Lateral Impulse on Kinetic Energy Projectiles in Flight
}

Bernard J. Guidos

Gene R. Cooper 
The findings in this report are not to be construed as an official Department of the Army position unless so designated by other authorized documents.

Citation of manufacturer's or trade names does not constitute an official endorsement or approval of the use thereof.

Destroy this report when it is no longer needed. Do not return it to the originator. 


\section{ERRATA SHEET}

RE: ARL-TR-2076, "The Effect of a Simple Lateral Impulse on Kinetic Energy Projectiles in Flight," by Bernard J. Guidos and Gene R. Cooper of the Weapons and Materials Research Directorate, U.S. Army Research Laboratory

Page 19, Equation (67), should have been

$$
\widetilde{\xi}^{\prime \prime}-M \widetilde{\xi}=\frac{\widetilde{q}_{l}^{*}}{\Delta s}\left[h\left(s-s_{l}+\Delta s_{l}\right)-h\left(s-s_{l}\right)\right]-\frac{\widetilde{z}_{l}^{*}}{\Delta s}\left[h^{\prime}\left(s-s_{l}+\Delta s_{l}\right)-h^{\prime}\left(s-s_{l}\right)\right] \quad \text { Eq (67) }
$$

Page 20, Equation (69), should have been

$$
\widetilde{\xi}=K_{1, n} e^{i \phi_{1, n}} e^{i \phi^{\prime}\left(s-s_{0}\right)}+K_{2, n} e^{i \phi_{2, n}} e^{-i \phi^{\prime}\left(s-s_{0}\right)}
$$




\section{Army Research Laboratory}

Aberdeen Proving Ground, MD 21005-5066

\section{The Effect of a Simple Lateral Impulse on Kinetic Energy Projectiles in Flight}

Bernard J. Guidos

Gene R. Cooper

Weapons \& Materials Research Directorate

Approved for public release; distribution is unlimited. 
Existing analytical theory for quantifying the free-flight motion of nonrolling, statically stable projectiles is extended to include the effect of a simple lateral impulse applied during flight. The extended theory is based on the incorporation of generalized lateral translational and angular disturbances into the familiar equations of projectile free-flight motion. The applied disturbances are then modeled using specified mathematical forms, and the modified equations are solved to obtain the angular and translational motion of the projectile over the trajectory. The various components of the translational motion of the projectile are extracted and characterized. An idealized application is presented for a large caliber finned projectile, representative of the class of $120-\mathrm{mm}$ long rod kinetic energy projectiles fired from the M1A1 Abrams tank, subjected to a single lateral control impulse in flight. The analytical closed form solutions are validated against results obtained using a numerical trajectory simulation code that incorporates generalized guidance and control commands. 


\section{ACKNOWLEDGMENTS}

The authors gratefully acknowledge Mr. John H. Whiteside, U.S. Army Tank-automotive Armament Command, for providing the technical review of the report; Dr. Mark F. Costello, Oregon State University, for providing guidance in the use of the numerical trajectory simulation code; and Drs. Peter Plostins, Paul Weinacht, and Mark L. Bundy, U.S. Army Research Laboratory, for reviewing the report manuscripts. 
INTENTIONALLY LEFT BLANK 
TABLE OF CONTENTS

$\underline{\text { Page }}$

LIST OF FIGURES $\ldots \ldots \ldots \ldots \ldots \ldots \ldots \ldots \ldots \ldots \ldots \ldots \ldots \ldots \ldots \ldots \ldots \ldots$

LIST OF TABLES $\ldots \ldots \ldots \ldots \ldots \ldots \ldots \ldots \ldots \ldots \ldots \ldots \ldots \ldots \ldots \ldots \ldots \ldots$

1. INTRODUCTION $\ldots \ldots \ldots \ldots \ldots \ldots \ldots \ldots \ldots \ldots \ldots \ldots \ldots \ldots \ldots$

2. IDEALIZED KE PROJECTILE $\ldots \ldots \ldots \ldots \ldots \ldots \ldots \ldots \ldots \ldots \ldots$

3. LATERAL DISPLACEMENT, ANGULAR DEVIATION, AND JUMP .... 3

4. APPLIED FORCE AND MOMENT DISTURBANCES $\ldots \ldots \ldots \ldots \ldots$

5. ANGULAR MOTION WITH SINGULAR IMPULSE $\ldots \ldots \ldots \ldots \ldots$

$5.1 \quad$ Equation of Angular Motion $\ldots \ldots \ldots \ldots \ldots \ldots \ldots \ldots \ldots \ldots \ldots$

$5.2 \quad$ Modal Parameters............................... 14

6. TRANSLATIONAL MOTION WITH SINGULAR IMPULSE $\ldots \ldots \ldots \ldots 16$

7. ANGULAR MOTION WITH SQUARE IMPULSE ........... 19

8. TRANSLATIONAL MOTION WITH SQUARE IMPULSE $\ldots \ldots \ldots \ldots 20$

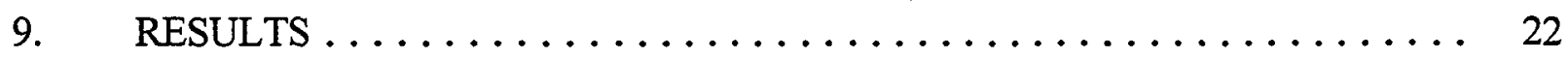

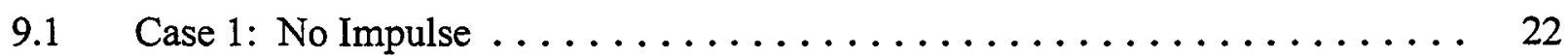

9.2 Case 2: In-Plane Impulse . . . . . . . . . . . . . . . 23

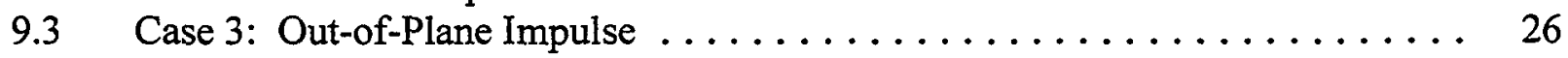

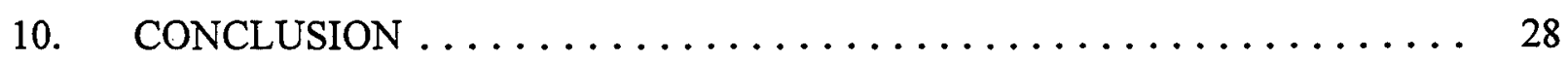

REFERENCES ............................ 31

APPENDIX

A. List of Symbols. . . . . . . . 33

DISTRIBUTION LIST $\ldots \ldots \ldots \ldots \ldots \ldots \ldots \ldots \ldots \ldots \ldots \ldots \ldots \ldots \ldots \ldots$

REPORT DOCUMENTATION PAGE $\ldots \ldots \ldots \ldots \ldots \ldots \ldots \ldots, 43$ 
INTENTIONALLY LEFT BLANK 


\section{LIST OF FIGURES}

Figure

$\underline{\text { Page }}$

1. Idealized KE Projectile and Lateral Jet $\ldots \ldots \ldots \ldots \ldots \ldots \ldots \ldots \ldots \ldots$

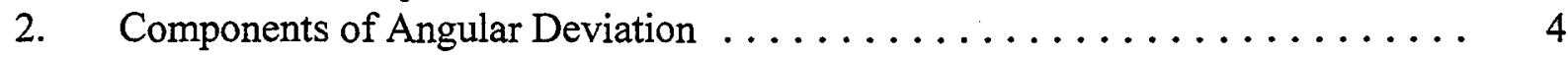

3. Square Wave Disturbance.......................... 6

4. Coordinate Systems .......................... 7

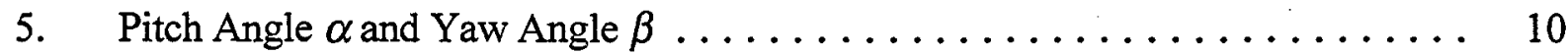

6. Illustration of Undamped Epicyclic Motion $\ldots \ldots \ldots \ldots \ldots \ldots \ldots \ldots \ldots$

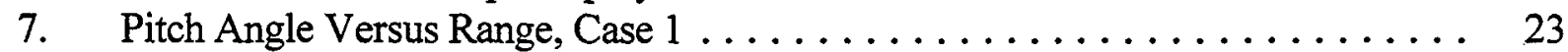

8. Vertical Displacement Versus Range, Cases 1 and $2 \ldots \ldots \ldots \ldots \ldots \ldots 24$

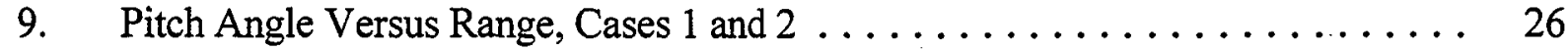

10. Vertical Displacement Versus Range, Cases 1 and $3 \ldots \ldots \ldots \ldots \ldots \ldots 27$

11. Horizontal Displacement Versus Range, Cases 1 and $3 \ldots \ldots \ldots \ldots \ldots .27$

12. Pitch and Yaw Angles Versus Range, Case $3 \ldots \ldots \ldots \ldots \ldots \ldots . \ldots . \ldots 28$ 
INTENTIONALLY LEFT BLANK 
LIST OF TABLES

Table

Page

1. Idealized Projectile and Lateral Jet Parameters . . . . . . . . . . . . . . 2 
INTENTIONALLY LEFT BLANK 


\section{THE EFFECT OF A SIMPLE LATERAL IMPULSE ON}

KINETIC ENERGY PROJECTILES IN FLIGHT

\section{INTRODUCTION}

The U.S. Army is developing precision-guided munition technologies to improve the accuracy and extend the range of its weapon systems. In-flight guidance and control of munitions involve the application of lateral course correction maneuvers that alter the angular and translational motions of the flight body. Such maneuvers are accomplished by applying one or more sets of prescribed translational and/or angular disturbances to the projectile during flight. These applied lateral disturbances can be delivered in a variety of ways, including fin/canard deflections or laterally thrusting jets. Disturbances of comparatively short duration can be characterized as impulsive and are of particular interest here.

In this report, a specific class of lateral impulsive disturbances is incorporated into the equations of motion for a finned, long rod, kinetic energy (KE) projectile. The procedure leads to closed form analytical solutions that show straightforward relationships to exist between the applied impulsive disturbances and the projectile angular and translational motion. The analytical expressions not only eliminate much of the computational overhead associated with the prediction of impulsively guided projectile motion but also lead to a generalized framework with which to analyze actual measured projectile motion or to design complex guidance and control maneuvers.

The objective here is to present the impulse model, incorporate it into the modified equations of motion, and validate the results with a 6-degrees-of-freedom (DOF) numerical trajectory simulation code that has guidance and control commands. Application is presented for an idealized large caliber finned KE projectile subjected to a single, simple in-flight lateral impulsive disturbance. Characterization is made of the projectile motion before and after the application of the lateral impulsive disturbance for some representative cases.

\section{IDEALIZED KE PROJECTILE}

An idealized $120-\mathrm{mm}$ finned $\mathrm{KE}$ projectile geometry is adopted to compare the analytical results with those from a numerical trajectory simulation code. Figure 1 illustrates the idealized 
projectile geometry. Table 1 shows the defining parameters of the projectile. The configuration represents the current class of $120-\mathrm{mm}$ armor-piercing, fin-stabilized, discarding sabot (APFSDS) $\mathrm{KE}$ ammunition fired from the Abrams M1A1 tank. These projectiles are commonly of large lengthto-diameter ratio, statically stable, damped, with low to moderate spin rates, launched in flat fire.

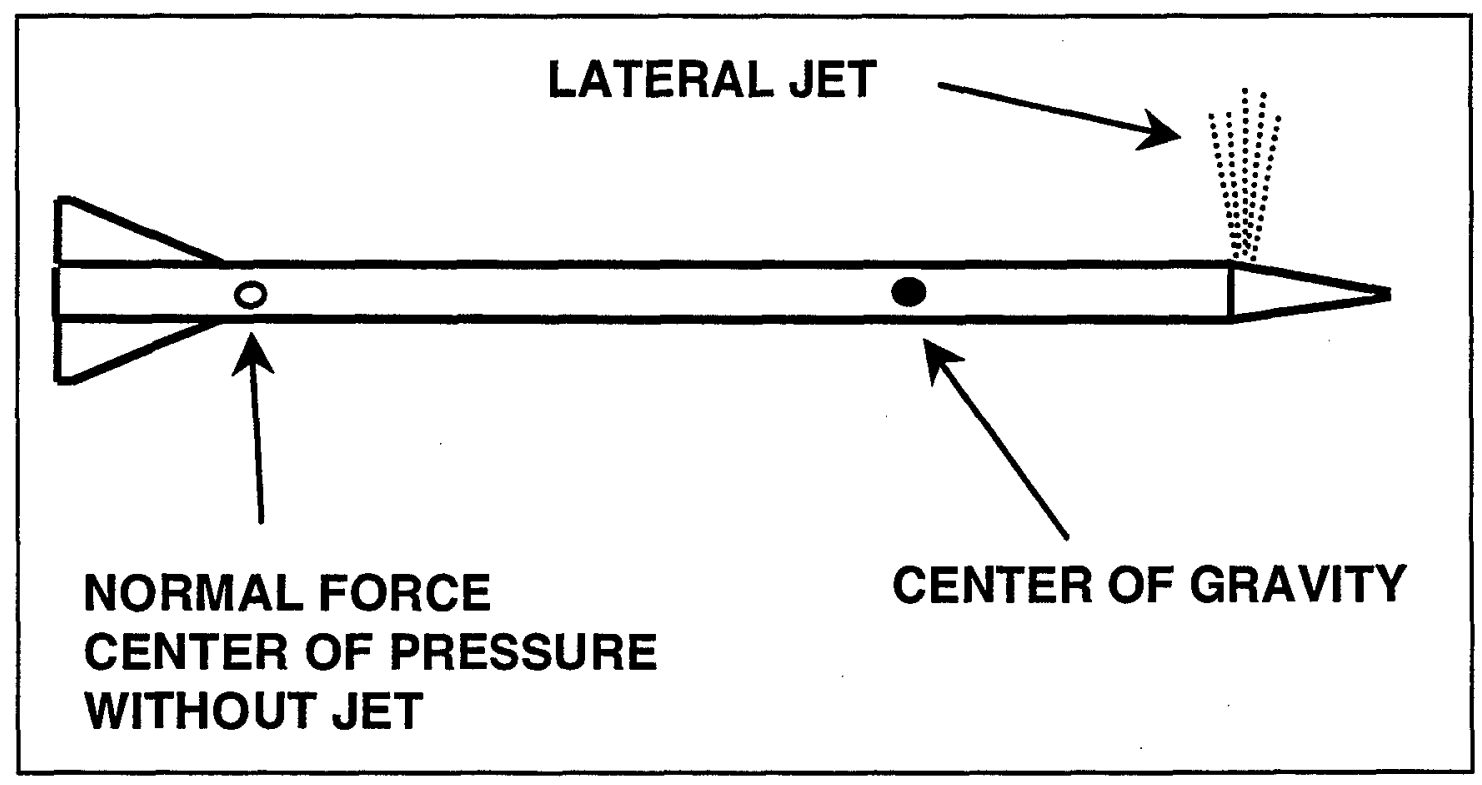

Figure 1. Idealized KE Projectile and Lateral Jet.

Table 1. Idealized Projectile and Lateral Jet Parameters

\begin{tabular}{|c|c|c|}
\hline & Metric & English \\
\hline Rod Diameter, $\boldsymbol{d}$ & $0.0254 \mathrm{~m}$ & $0.08333 \mathrm{ft}$ \\
\hline Mass, $\boldsymbol{m}$ & $5.0 \mathrm{~kg}$ & $11.023 \mathrm{lbm}$ \\
\hline Length & $0.8 \mathrm{~m}$ & $2.62467 \mathrm{ft}$ \\
\hline Center of Gravity (CG) from Base & $0.5 \mathrm{~m}$ & $1.6404 \mathrm{ft}$ \\
\hline Transverse Moment of Inertia, $\boldsymbol{I}_{\boldsymbol{t}}$ & $0.2 \mathrm{~kg}-\mathrm{m}^{2}$ & $0.1475125 \mathrm{slug}-\mathrm{ft}^{2}$ \\
\hline Pitching Moment Coefficient, $\boldsymbol{C}_{\boldsymbol{M} \alpha}$ & $-100 \mathrm{cal} / \mathrm{rad}$ & $-100 \mathrm{cal} / \mathrm{rad}$ \\
\hline Lift Force Coefficient, $\boldsymbol{C}_{\boldsymbol{L} \alpha}$ & $10 / \mathrm{rad}$ & $10 / \mathrm{rad}$ \\
\hline Location of Lateral Jet Relative to CG, $\boldsymbol{d}_{\boldsymbol{F}}$ & $0.2 \mathrm{~m}$ & $0.6563 \mathrm{ft}$ \\
\hline Jet Impulse Magnitude, $\boldsymbol{B}_{1}{ }^{*}$ & $1.0 \mathrm{~N}-\mathrm{s}$ & $0.22481 \mathrm{lbf}-\mathrm{s}$ \\
\hline
\end{tabular}

The projectile is assumed to be perfectly symmetrical. The aerodynamic pitch-plane center of pressure is determined from the prescribed values of pitching moment coefficient $C_{M \alpha}$ and lift force coefficient $C_{L \alpha .}$. The projectile is prescribed to have a lateral impulse jet situated at an axial 
location that would correspond to a location on the windshield, near the shoulder. The lateral impulse jet is prescribed to have a total impulse of $1 \mathrm{~N}$-s, typical of an off-the-shelf component.

\section{LATERAL DISPLACEMENT, ANGULAR DEVIATION, AND JUMP}

The target impact of tank-fired rounds has been traditionally characterized in terms of jump. The jump associated with a particular shot can be defined using the nomenclature introduced in Figure 2. The boresight line of fire (LOF) is established as the line connecting the center of the muzzle and the visual aim point (boresight point) that would be obtained by a muzzle borescope. The gravity drop is extracted separately from various data sources and is considered known. The LOF and gravity drop together establish an aim point, from which the target impact point is measured. The vector that connects the aim point and target impact point is considered here to be the lateral displacement. The horizontal and vertical components of the lateral displacement are $Z_{T}$ and $Y_{T}$, respectively. The lateral displacement is converted into an angle, in units of radians, when divided by range. This angle, denoted as $\vec{\theta}$ represents the total angular deviation of the projectile from the intended flight path as measured from the muzzle, i.e.,

$$
\bar{\theta}=\theta_{V} \bar{J}+\theta_{H} \bar{K}=\frac{Y_{T}}{X_{T}} \bar{J}+\frac{Z_{T}}{X_{T}} \bar{K}
$$

in which $\theta_{H}$ and $\theta_{V}$ are the horizontal and vertical components, respectively. The unit vector $\bar{J}$ is oriented upward (along the positive $Y$ axis in the figure), and the unit vector $\bar{K}$ is oriented to the gunner's right (along the positive $Z$ axis in the figure), and these physical orientations constitute range coordinates as used in this report.

The angular deviation of the projectile is commonly discussed in flight dynamics theory using complex notation (to be introduced subsequently) and denoted here as $\tilde{\theta}$. In the complex notation to be used here, the vertical component is oriented along a real coordinate axis and the horizontal component is oriented along an imaginary coordinate axis, i.e.,

$$
\tilde{\theta}=\theta_{V}+i \theta_{H}
$$

with $i$ equal to $\sqrt{-1}$. 


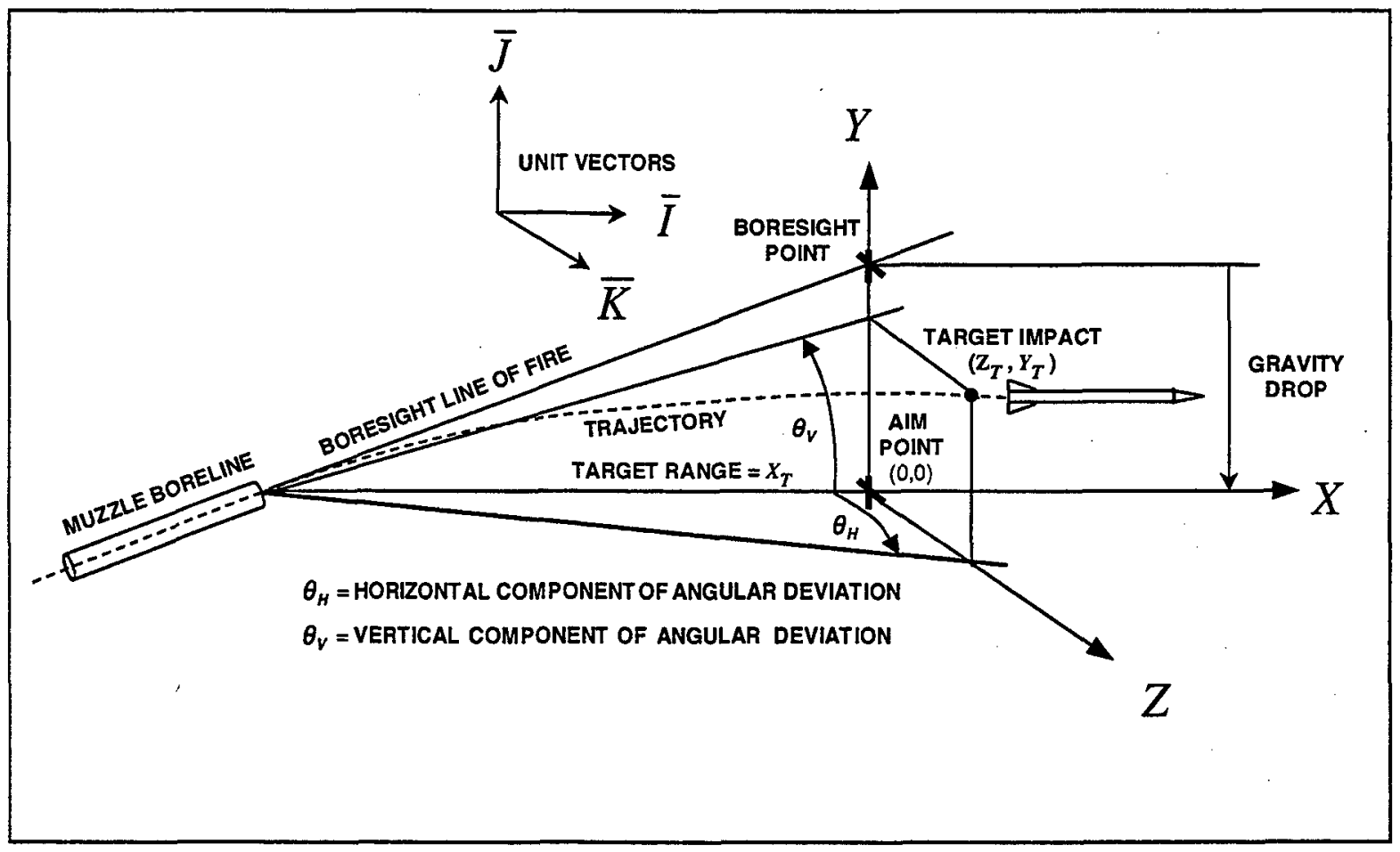

Figure 2. Components of Angular Deviation.

At typical engagement ranges, the angular deviation of tank-fired $\mathrm{KE}$ ammunition, historically consisting of unguided projectiles, is, for practical purposes, constant. In that case, the lateral displacement of the projectile is proportional to range and it can be said that the angular deviation of the projectile at the target corresponds to the jump attributable to the tank launch event. However, at these same typical ranges, the lateral displacement of a guided tankfired KE projectile is typically not proportional to range after a mid-flight course correction maneuver is applied. As a result, the angular deviation of the projectile at the target is not likely to correspond to the jump attributable to the tank launch event. These observations, supported by the mathematical development to be presented subsequently, produce discussions herein that focus on the lateral displacement and angular deviation of the projectile, rather than on the more traditional quantity of jump.

\section{APPLIED FORCE AND MOMENT DISTURBANCES}

In free flight, the projectile is acted upon by a lateral impulsive disturbance. The disturbance can be separated into a translational component (i.e., force) $\vec{F}$ and an angular 
component (i.e., moment) $\vec{M}$, both defined as functions of time. In range coordinates and vector form they are

$$
\begin{aligned}
& \vec{F}=\vec{F}(t)=F_{Y} \bar{J}+F_{Z} \bar{K} \\
& \vec{M}=\vec{M}(t)=M_{Y} \bar{J}+M_{Z} \bar{K}
\end{aligned}
$$

in which the usual right-hand rule applies to the moment components.

The forms of the lateral disturbances $\vec{F}$ and $\vec{M}$ are completely general in actual projectile flight. The approach introduced here specifies simple modeled forms of the impulsive disturbances that can be extended and used in more advanced applications to model actual, more generalized, disturbances. Two basic mathematical forms of applied impulsive disturbances are of interest here. The first is a single, positive phase duration, unidirectional square wave disturbance. The disturbance has the form

$$
\vec{F}_{1}=F_{1}\left[\cos \phi_{1} \bar{J}+\sin \phi_{1} \bar{K}\right]
$$

in which the subscript 1 denotes one of any number of disturbances that could be modeled. The orientation of the applied lateral disturbance is measured from the vertical direction in the earthfixed frame, is denoted $\phi_{1}$, and is constant. The magnitude is $F_{1}$ with the restriction

$$
F_{1}=F_{1}(t)=C_{1}\left[h\left(t-t_{1}+\Delta t_{1}\right)-h\left(t-t_{1}\right)\right] \quad \text { for } \quad t-\Delta t_{1}<t<t_{1} \quad \text { Eq (5) }
$$

in which $C_{I}$ is a real constant and $h\left(t-t_{l}\right)$ is the Heaviside unit step function occurring at $t_{1}$ (Lighthill 1958). The form of $F_{1}$ is illustrated in Figure 3, and this form of applied disturbance is henceforth simply referred to as a square disturbance. The disturbance creates intervals and sub-intervals, also illustrated in Figure 3, with which motion parameters will eventually be associated. Concurrently, the disturbance can be described in terms of distance along the flight path, $s$, as illustrated.

The second form of impulsive disturbance considered here is a singular disturbance. A specific form of the square disturbance, it is defined here in the same manner as the square disturbance but with the additional restriction that $\Delta t_{1}=0$. 


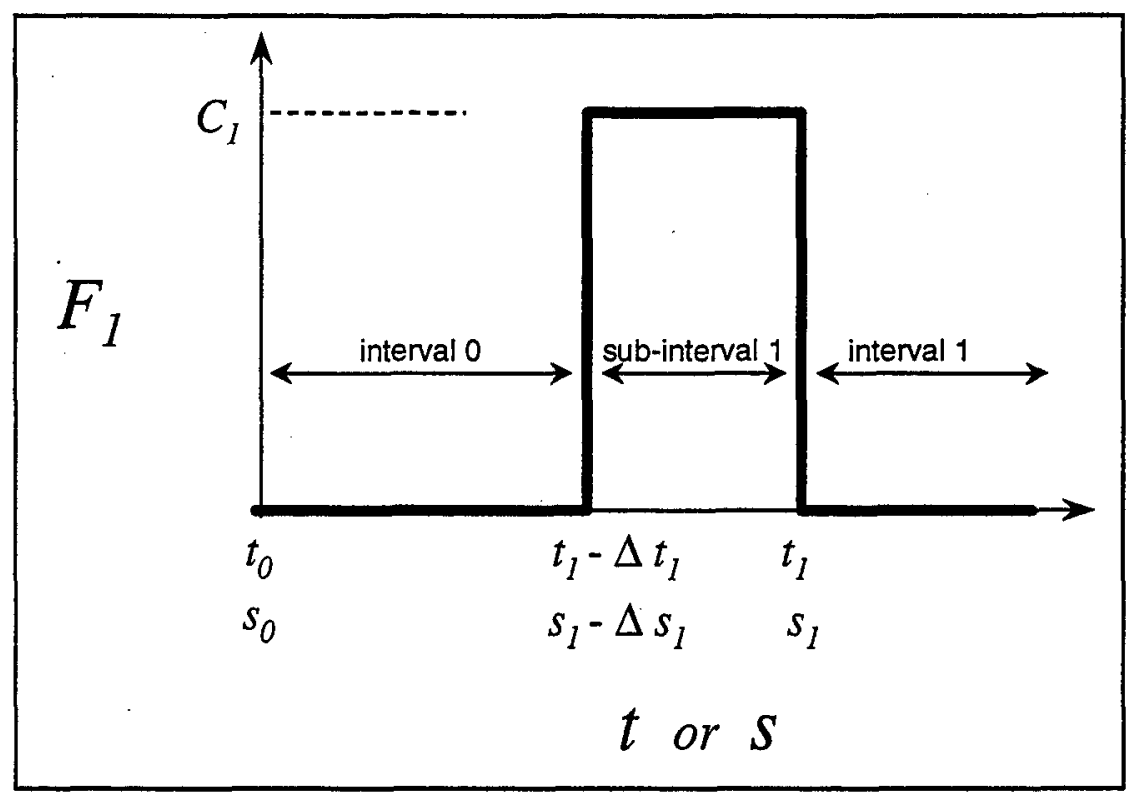

Figure 3. Square Wave Disturbance.

The singular disturbance is the most important form for representing actual disturbances. First, it is the most basic form of an impulsive disturbance, forming a building block with which to model more complicated impulses and motions. Second, it is the most mathematically simple form with which to work.

The modeled force and moment disturbances are to be incorporated into the free-flight equations of motion that are presented and solved by Murphy (1963) and McCoy (1998). McCoy's coordinate systems are adopted here and illustrated in Figure 4 . The $(\bar{I}, \bar{J}, \bar{K})$ system is the earth-fixed range system, the $(\bar{i}, \bar{j}, \bar{k})$ system is a non-rolling system aligned with the velocity vector, and the $(\bar{x}, \bar{y}, \bar{z})$ system is a body-fixed system. For flat fire trajectories, the unit vector $\bar{j}$ is usually aligned to within $1^{\circ}$ or less with the unit vector $\bar{J}$, and the unit vector $\bar{k}$ is usually aligned even closer with the unit vector $\bar{K}$. 


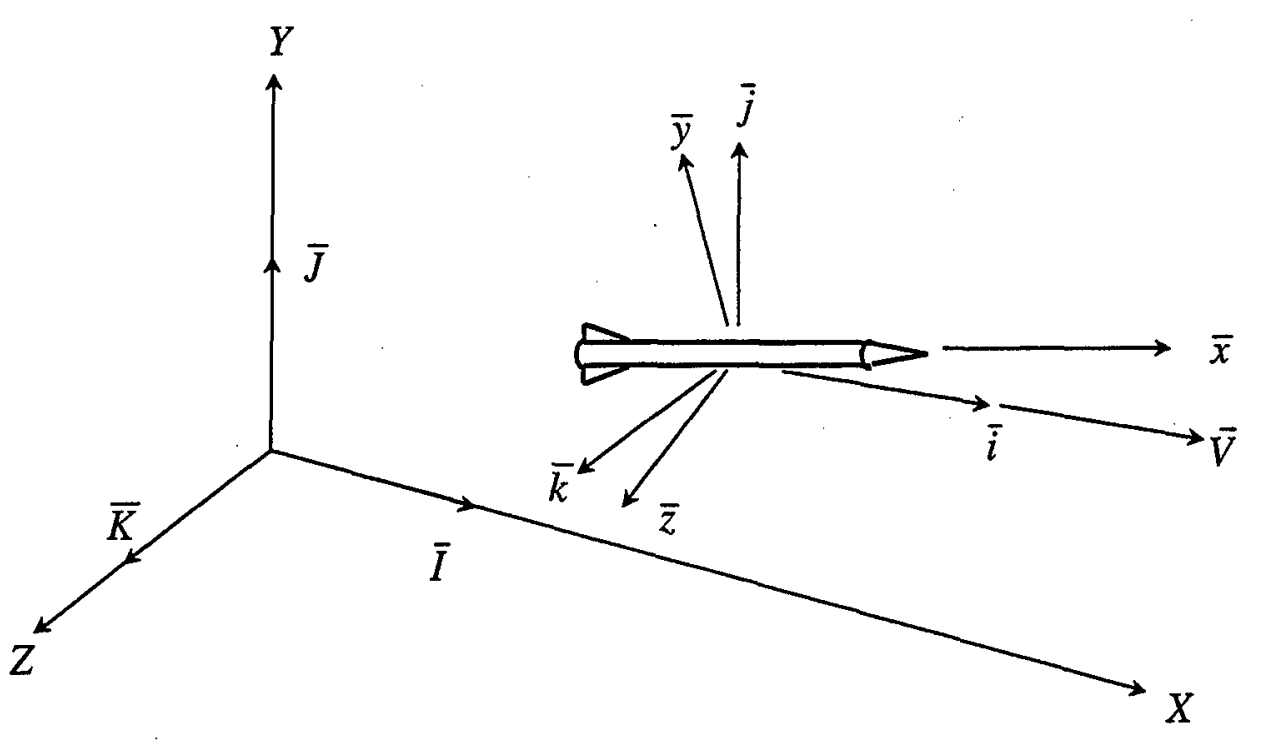

Figure 4. Coordinate Systems.

The ensuing development requires that the applied lateral force and moment disturbances be cast in complex notation consistent with $\mathrm{McCoy}$, and the following complex representations are defined as

$$
\begin{aligned}
& \tilde{F}_{l}=F_{Y}+i F_{z} \\
& \tilde{M}_{I}=M_{Z}-i M_{Y}
\end{aligned}
$$

in which $i$ is the square root of -1 . The applied disturbances are nondimensionalized to form corresponding complex nondimensional force and moment coefficients, $\widetilde{C}_{N I}$, and $\tilde{C}_{M I}$, respectively

$$
\begin{aligned}
& \tilde{C}_{N I}=\tilde{C}_{N I}(t)=\frac{\tilde{F}_{1}}{1 / 2 \rho V^{2} A} \\
& \tilde{C}_{M I}=\tilde{C}_{M I}(t)=\frac{\tilde{M}_{1}}{1 / 2 \rho V^{2} A d}
\end{aligned}
$$

The ensuing development also requires the formation of "starred" quantities, obtained by multiplying the original quantity with the density factor, i.e., 


$$
\begin{aligned}
& \tilde{C}_{N 1}^{*}=\frac{\rho A d}{2 m} \tilde{C}_{N I} \\
& \tilde{C}_{M I}^{*}=\frac{\rho A d}{2 m} \tilde{C}_{M I}
\end{aligned}
$$

The corresponding nondimensional generalized translational and angular impulses are $\tilde{\mathcal{F}}_{1}^{*}$ and $\tilde{\mathscr{M}}_{1}^{*}$, respectively. These impulses are complex constants found by integrating the applied disturbances over the duration of the disturbances, i.e.,

$$
\begin{gathered}
\tilde{z}_{1}^{*}=\int_{s_{1}}^{s_{1}} \tilde{C}_{N 1}^{*} d s \\
\tilde{\mathscr{M}}_{1}^{*}=\int_{s_{1}} \int_{\Delta s_{1}}^{s_{1}} \tilde{C}_{M 1}^{*} d s
\end{gathered}
$$

The integrations are performed with respect to flight path $s$, the disturbances end at $s_{l}$, the spatial duration of the disturbances is $\Delta s_{1}$, and the appropriate transformation of the limits of integration from time $t$ to distance along the flight path $s$ is applied.

The horizontal and vertical components of the translational impulse are defined in the complex notation as

$$
\tilde{\xi}_{I}^{*}=\xi_{Y}^{*}+i \xi_{Z}^{*}
$$

The translational impulse can be written in polar form as

$$
\tilde{\xi}_{1}^{*}=\xi_{1}^{*} e^{i \phi_{1}}
$$

in which $\mathcal{F}_{I}^{*}$ and $\phi_{1}$ are the magnitude and orientation, respectively, of the translational lateral impulse.

The applied force vector associated with, for example, a lateral jet, is typically coplanar with and perpendicular to the projectile axis. If the pitch and yaw angles are small, then the 
components of the force vector may be assumed to correspond to the horizontal and vertical coordinate directions without additional transformation. Prescribe the applied force vector to act upon the body at an axial distance $d_{F}$ from the projectile center of gravity (CG). The sign of $d_{F}$ is positive for a case in which the force is applied forward of the CG (e.g., near the nose tip). The relationship between the applied force and moment is prescribed as

$$
\tilde{M}_{l}=\tilde{F}_{l} d_{F}
$$

By substituting into the expressions already introduced, the relationship between the applied force and moment impulses is found to be

$$
\tilde{\mathscr{M}}_{1}^{*}=\frac{\tilde{\nexists}_{1}^{*} d_{F}}{d}
$$

The assumed relationship between the applied force and moment is convenient to satisfy the objectives of the current report. More accurate (and complex) expressions to define the applied force and moment disturbances can be used to refine the development of the theory for specific applications. For example, the expressions employed here, both in the analytical and numerical approaches, do not model the jet-body interactions.

\section{ANGULAR MOTION WITH SINGULAR IMPULSE}

\subsection{Equation of Angular Motion}

The complex yaw angle relative to the flight path is defined consistent with McCoy (1998):

$$
\tilde{\xi}=\alpha+i \beta
$$

with the pitch angle $\alpha$ being positive for nose up and the yaw angle $\beta$ being positive for nose right from the gunner's perspective, as shown in Figure 5. 


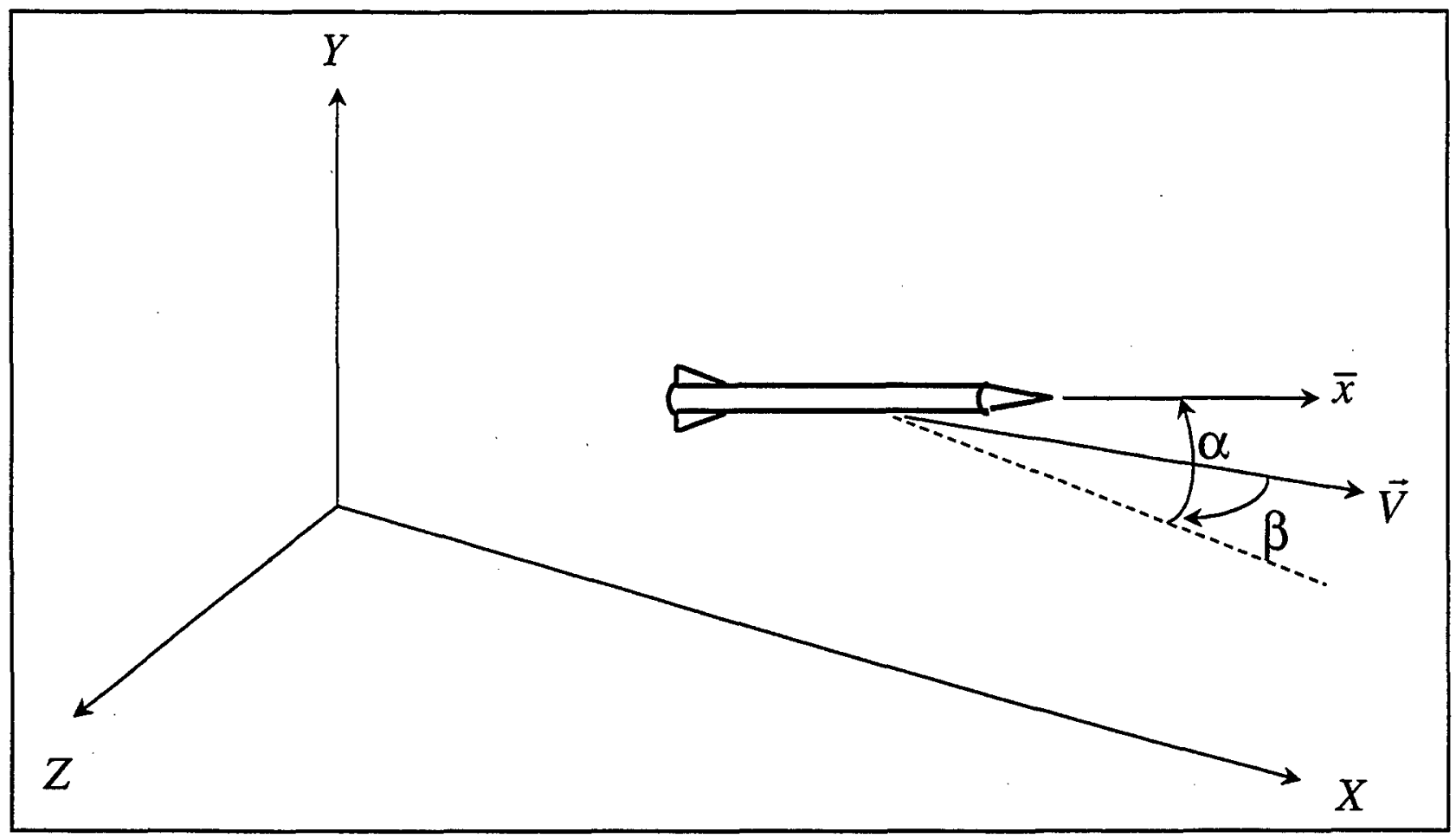

Figure 5. Pitch Angle $\alpha$ and Yaw Angle $\beta$.

The projectile is assumed to be symmetrical, non-spinning, statically stable, and in flat fire. Damping, while important for certain aspects of the projectile motion, is neglected here in order to focus attention on the analytical model methodology. Under these assumptions, the linearized free-flight equation of angular motion with no applied lateral impulse as given by McCoy (1998) can be reduced to

$$
\tilde{\xi}^{\prime \prime}-M \widetilde{\xi}=0
$$

in which the superscript prime denotes differentiation with respect to the flight path $s$ and

$$
M=1 / 2 \rho A d^{3} C_{M \alpha} / I_{t}
$$

Now consider the single set of applied translational and angular impulsive lateral disturbances, $\tilde{C}_{N 1}^{*}$ and $\tilde{C}_{M 1}^{*}$, respectively, discussed in the previous section. The free-flight equation of angular motion can be re-derived with these terms included, giving the more generalized equation of angular motion as 


$$
\widetilde{\xi}^{\prime \prime}-M \widetilde{\xi}=\frac{\tilde{C}_{M 1}^{*}}{k_{t}^{2}}-\left(\tilde{C}_{N 1}^{*}\right)^{\prime}
$$

in which $k_{t}$ is the transverse radius of gyration, with the definition

$$
k_{t}^{2}=\frac{I_{t}}{m d^{2}}
$$

If the impulses attributed to $\tilde{C}_{N I}^{*}$ and $\tilde{C}_{M I}^{*}$ are modeled as singular, then Equation (21) can be written as

$$
\tilde{\xi}^{\prime \prime}-M \widetilde{\xi}=\frac{\tilde{M}_{l}^{*}}{k_{t}^{2}} \delta\left(s-s_{l}\right)-\tilde{\mathcal{Z}}_{l}^{*} \delta^{\prime}\left(s-s_{l}\right)
$$

in which the Dirac delta function (Lighthill 1958), $\delta\left(s-s_{1}\right)$, is used.

This approach is analogous to that used by Cooper and Fansler (1997) to model the impulsive effect of yaw card impacts on the angular motion of spinning projectiles. The major difference (aside from the zero spin assumption) is that the directionality of the angular and translational impulsive disturbances has been generalized. Also, the present effort focuses on a single set of angular and translational disturbances, while the effort by Cooper and Fansler was generalized for successive impulses.

For convenience, the following definition is used:

$$
\tilde{q}_{1}^{*}=\frac{\tilde{m}_{1}^{*}}{k_{t}^{2}}
$$

Then the general solution to the angular equation can be written as

$$
\begin{aligned}
& \tilde{\xi}=K_{1,0} e^{i \phi_{1,0}} e^{i \phi_{1,0}^{\prime}\left(s-s_{0}\right)}+K_{2,0} e^{i \phi_{2,0} e^{i \phi_{2,0}^{\prime}\left(s-s_{0}\right)}} \\
& +1 / 2 h\left(s-s_{I}\right)\left[i \tilde{\emptyset}_{1}^{*}\left(\frac{e^{i \phi_{1,1}^{\prime}\left(s-s_{1}\right)}}{\phi_{1,1}^{\prime}}+\frac{e^{i \phi_{2,1}^{\prime}\left(s-s_{1}\right)}}{\phi_{2,1}^{\prime}}\right)-\tilde{\mathcal{F}}_{1}^{*}\left(e^{i \phi_{1,1}^{\prime}\left(s-s_{1}\right)}+e^{i \phi_{2,1}^{\prime}\left(s-s_{I}\right)}\right)\right]
\end{aligned}
$$

The solution in the $n$th interval (here, $n$ is either 0 or 1 ) can be written in a form analogous to the free-flight cases given by Murphy and McCoy, referred to here as modal form: 


$$
\tilde{\xi}=K_{1, n} e^{i \phi_{1, n}} e^{i \phi_{1, n}^{\prime}\left(s-s_{0}\right)}+K_{2, n} e^{i \phi_{2, n}} e^{i \phi_{2, n}^{\prime}\left(s-s_{0}\right)}
$$

in which the modal parameters are defined as follows:

$K_{i, n}=$ magnitude of first epicyclic modal arm for $n t h$ interval, real and positive

$K_{2, n}=$ magnitude of second epicyclic modal arm for $n t h$ interval, real and positive

$\phi_{1, n}=$ reference phase angle of first epicyclic modal arm for $n$th interval, evaluated at $s=s_{0}$ and real

$\phi_{2, n}=$ reference phase angle of second epicyclic modal arm for $n t h$ interval, evaluated at $s=s_{0}$ and real

$\phi_{1, n}^{\prime}=$ turning rate of first epicyclic modal arm for $n$th interval, real

$\phi_{2, n}^{\prime}=$ turning rate of second epicyclic modal arm for $n$th interval, real

Because the spin is assumed to be zero, the turning rates are related by

$$
\phi^{\prime}=\phi_{1, n}^{\prime}=-\phi_{2, n}^{\prime}
$$

in which the magnitudes of the rates are assumed to be constant in all intervals throughout the flight. The usual relationship between the pitching moment coefficient and modal turning rate for a non-spinning projectile is retained:

$$
\phi^{\prime 2}=-\frac{C_{M \alpha}^{*}}{k_{t}^{2}}=-M
$$

The modal form of the solution, as given by Equation (26), is a parametric equation for an ellipse representing the modeled undamped epicyclic motion and is illustrated in Figure 6 . The two terms on the right-hand side of Equation (26) are the two epicyclic modal arms, represented as vectors in the $\alpha, \beta$ complex plane. For one full cycle of motion, the summation of the two vectors etches the image of an ellipse in the complex plane. The eccentricity of the ellipse is determined by the relative magnitudes of the two modal arms. If the magnitudes of the two modal arms are equal $\left(K_{1, n}=K_{2, n}\right)$, then the angular motion is planar. If the magnitude of one of the two modal arms is zero, then the angular motion is circular. 


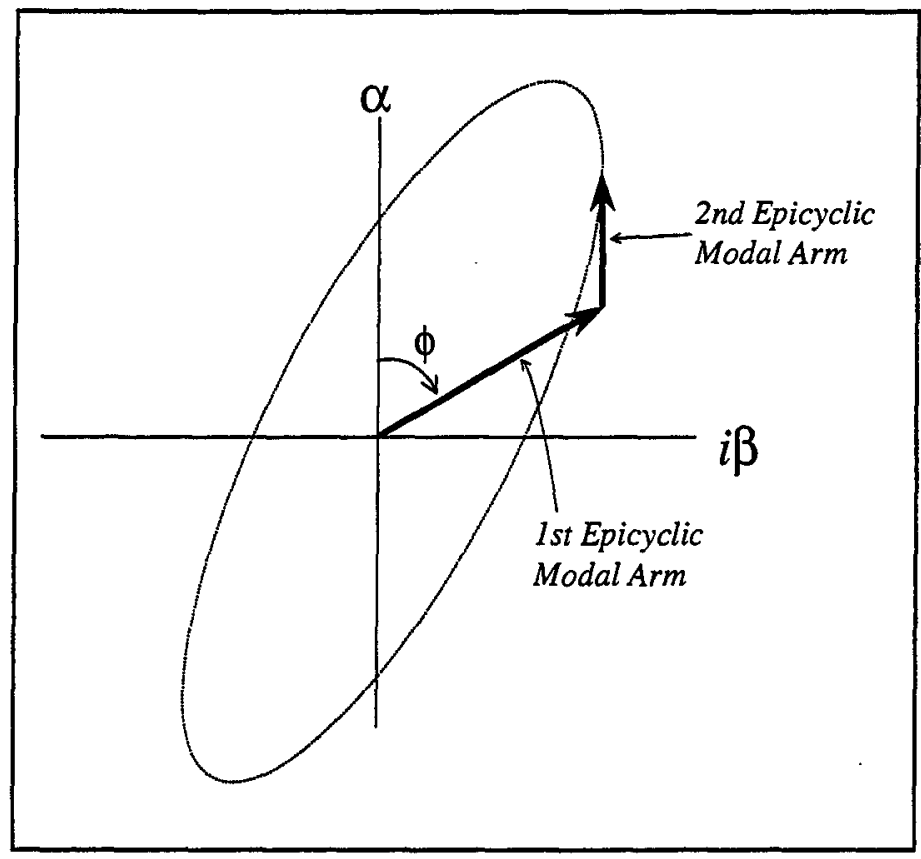

Figure 6. Ilustration of Undamped Epicyclic Motion.

The solution to Equation (24) yields two conditions at $s_{1}$. The first condition is

in which

$$
\tilde{\xi}_{1+}=\tilde{\xi}_{1-}-\tilde{\xi}_{1}^{*}
$$

$$
\begin{aligned}
& \widetilde{\xi}_{1+}=\tilde{\xi}\left(s_{1}^{+}\right) \\
& \tilde{\xi}_{1-}=\tilde{\xi}\left(s_{I}^{-}\right)
\end{aligned}
$$

The second condition is

$$
\tilde{\xi}_{I+}^{\prime}=\tilde{\xi}_{I-}^{\prime}+\tilde{q}_{1}^{*}
$$

in which

$$
\begin{aligned}
& \tilde{\xi}_{l+}^{\prime}=\tilde{\xi}^{\prime}\left(s_{l}^{+}\right) \\
& \tilde{\xi}_{l=}^{\prime}=\tilde{\xi}^{\prime}\left(s_{l}^{-}\right)
\end{aligned}
$$

The subscripts 1 - and $1+$ represent the quantity immediately before and after the application of the singular impulse. The first condition recognizes that a discontinuity in projectile yaw exists at $s_{1}$ for a non-zero singular translational disturbance. The second condition recognizes that a discontinuity exists in the projectile angular rate at $s_{1}$ for a non-zero singular angular disturbance. The solution of the equation of angular motion has the same mathematical form as the free-flight 
solution given by Murphy and McCoy, but with additional sets of conditions occurring where the singular impulsive disturbances are applied.

\subsection{Modal Parameters}

The modal parameters given previously have long been used to characterize aeroballistic flight in the absence of applied in-flight impulses. The modal parameters in adjacent intervals can be related to each other and to the impulses experienced during flight. Following the same procedure as Cooper and Fansler (1997), the reference complex modal arms of the nth interval are defined as

$$
\begin{aligned}
& \tilde{\aleph}_{1, n}=K_{1, n} e^{i \phi_{1, n}} \\
& \tilde{\aleph}_{2, n}=K_{2, n} e^{i \phi_{2, n}}
\end{aligned}
$$

Then the reference complex modal arms in the two adjacent intervals are related by

$$
\begin{aligned}
& \tilde{\bar{x}}_{1,1}=\tilde{\bar{x}}_{1,0}-1 / 2\left(\frac{i \tilde{\tilde{g}}_{1}^{*}}{\phi^{\prime}}+\tilde{\xi}_{1}^{*}\right) e^{-i \phi^{\prime}\left(s_{1}-s_{0}\right)} \\
& \tilde{\bar{x}}_{2,1}=\tilde{\bar{x}}_{2,0}+1 / 2\left(\frac{i \tilde{\tilde{g}}_{1}^{*}}{\phi^{\prime}}-\tilde{\xi}_{1}^{*}\right) e^{i \phi^{\prime}\left(s_{1}-s_{0}\right)}
\end{aligned}
$$

The relative contributions to the angular motion from the applied translational and angular impulses can now be ascertained by comparing the magnitudes of the terms $\left(\tilde{g}_{1}^{*} / \phi^{\prime}\right)$ and $\tilde{\mathcal{F}}_{1}^{*}$. The comparison can be made by substituting the assumed relationship between the applied translational and angular impulses, rewritten here as

$$
\tilde{g}_{1}^{*}=\frac{\tilde{\xi}_{1}^{*} d_{F}}{k_{t}^{2} d}
$$

For the idealized projectile and lateral jet configuration prescribed here, the contribution from the angular disturbance is found to be approximately 80 times greater than the contribution from the translational impulse. The angular motions of interest here are already limited to total angles of attack in the linear range, i.e., a few degrees. Therefore, it is prudent in the present work to drop 
the applied translational impulse contribution to the angular motion and retain only the applied angular impulse contribution. This may not be acceptable for cases in which the lateral jet is located closer to the projectile CG and/or the magnitude of the translational impulse is larger.

The values of the modal parameters, $K_{1, n}, K_{2, n}, \phi_{1, n}, \phi_{2, n}$ under these assumptions are now obtained. The applied angular impulse is characterized in complex polar form as follows:

$$
\tilde{g}_{1}^{*}=q_{1}^{*} e^{i \phi_{1}}
$$

in which the orientation of the angular impulse is $\phi_{1}$ as previously defined and

$$
g_{1}^{*}=\left|\tilde{g}_{1}^{*}\right| \operatorname{sign}\left(d_{F}\right)
$$

The scalar quantity $g_{1}^{*}$, which can be positive or negative, represents both the magnitude and sign of the angular impulse within the specified orientation. The following functional definition is specified:

$$
\operatorname{sign}\left(d_{F}\right)=\left\{\begin{array}{cl}
1 & \text { for } d_{F} \geq 0 \\
-1 & \text { for } d_{F}<0
\end{array}\right.
$$

The relationship between the modal arms in adjacent intervals is then

$$
\begin{aligned}
& K_{1,1}^{2}=K_{1,0}^{2}+\frac{\eta_{1}^{*^{2}}}{4 \phi^{\prime 2}}-\frac{K_{1,0} \eta_{1}^{*}}{\phi^{\prime}} \sin \Phi_{1,1} \\
& K_{2,1}{ }^{2}=K_{2,0}{ }^{2}+\frac{\eta_{1}^{* 2}}{4 \phi^{\prime 2}}+\frac{K_{2,0} \eta_{1}^{*}}{\phi^{\prime}} \sin \Phi_{2,1}
\end{aligned}
$$

in which

$$
\begin{aligned}
& \Phi_{1,1}=\phi_{1,0}+\left(s_{1}-s_{0}\right) \phi^{\prime}-\phi_{I} \\
& \Phi_{2.1}=\phi_{2,0}-\left(s_{1}-s_{0}\right) \phi^{\prime}-\phi_{1}
\end{aligned}
$$

The phase shifts of the modal arms are then given by

$$
\phi_{1,1}-\phi_{1,0}=\tan ^{-1} \frac{\eta_{1}^{*} \cos \Phi_{1,1}}{\eta_{1}^{*} \sin \Phi_{1,1}-2 \phi^{\prime} K_{1,0}}
$$




$$
\phi_{2,1}-\phi_{2,0}=\tan ^{-1} \frac{\eta_{1}^{*} \cos \Phi_{2,1}}{\eta_{1}^{*} \sin \Phi_{2,1}+2 \phi^{\prime} K_{2,0}}
$$

\section{TRANSLATIONAL MOTION WITH SINGULAR IMPULSE}

The translational motion, also called "swerve," is the motion of the projectile CG. Using McCoy's coordinate system, the free-flight swerve equation with no applied in-flight impulse given by McCoy can be written in complex notation as

$$
y^{\prime \prime}+i z^{\prime \prime}=C_{L \alpha}^{*} \tilde{\xi}-g / m
$$

in which $y$ and $z$ (not related to the $\bar{y}$ and $\bar{z}$ unit vectors mentioned previously) are defined as

$$
\begin{aligned}
& y=Y / d \\
& z=Z / d
\end{aligned}
$$

The left-hand side is the lateral acceleration of the projectile CG. The right-hand side is the sum of aerodynamic and gravitational forces divided by the projectile mass.

The equation can be modified to include the applied in-flight force and moment impulses, giving

$$
y^{\prime \prime}+i z^{\prime \prime}=C_{L \alpha}^{*} \tilde{\xi}+\tilde{C}_{N 1}^{*}-g / m
$$

The right-hand side now contains the applied translational disturbance $\tilde{C}_{N 1}^{*}$. Also, the functional form of the complex angle of attack on the right-hand side now contains the additional terms representing the angular effects of the applied impulses. For the singular impulse model, the equation can be written as

$$
y^{\prime \prime}+i z^{\prime \prime}=C_{L \alpha}^{*} \widetilde{\xi}+\tilde{Ұ}_{1}^{*} \delta\left(s-s_{1}\right)-g / m
$$

The functional form of the complex angle of attack on the right-hand side now contains the additional terms representing the effects of the singular impulse on the angular motion, as given by Equation (25). The solution to this differential equation can be written as 


$$
\tilde{r}=\tilde{r}_{0}+\tilde{r}_{0}^{\prime}\left(s-s_{0}\right)+\tilde{r}_{T}+\tilde{r}_{L}
$$

The lateral displacement of the projectile CG is denoted here as $\tilde{r}$ and written in complex notation as

$$
\tilde{r}=\left(y-y_{g}\right)+i z
$$

in which the gravity drop, $y_{g}$, is removed from further consideration. The gravity drop is discussed by both Murphy (1963) and McCoy (1998) and remains unchanged from the free-flight case and is considered known. Before addressing the individual terms on the right-hand side of Equation (54), it is noted that, following the discussion of Section 3, the lateral displacement is related to the angular deviation by

$$
\tilde{\theta}=\frac{\tilde{r}}{x}
$$

The first two terms describing the projectile lateral motion, $\tilde{r}_{0}$ and $\tilde{r}_{0}^{\prime}\left(s-s_{0}\right)$, are initial conditions evaluated at $s=s_{0}$. The term $\tilde{r}_{0}$ is the projectile CG's lateral location at $s_{0}$ and is typically taken to be zero, i.e., the origin of the range coordinate system. This term's contribution to angular deviation, obtained by dividing it by range $\left(s-s_{0}\right)$ is effectively zero. The term $\tilde{r}_{0}^{\prime}\left(s-s_{0}\right)$ is the lateral displacement of the projectile attributable to its lateral velocity at $s_{0}$, and this term's contribution to the angular deviation is constant with respect to range.

The third term is the non-aerodynamic component of the lateral displacement attributable to the translational impulse and is denoted $\tilde{r}_{T}$. For the singular impulse model, the term can be written as follows, with $r_{1}$ and $r_{2}$ being dummy variables:

$$
\tilde{r}_{T}=\int_{s_{0}}^{s} \int_{s_{0}}^{r_{2}} \tilde{z}_{1}^{*} \delta\left(s-s_{1}\right) d r_{1} d r_{2}
$$

The term can be evaluated in the first interval as

$$
\tilde{r}_{T}=\left(s-s_{1}\right) \tilde{\xi}_{1}^{*}
$$


Because the angular data can often be obtained more accurately in testing than the translational data can, a useful alternate expression for $\tilde{r}_{T}$ is obtained by substituting the relationship between the applied translational and angular impulses, giving, in the first interval,

$$
\tilde{r}_{T}=\left(s-s_{1}\right) \tilde{g}_{1}^{*} k_{t}^{2} d / d_{F}
$$

This term's contribution to the projectile angular deviation at range $\left(s-s_{0}\right)$ is denoted here as $\tilde{\theta}_{T}$ and is given in radians as

$$
\tilde{\theta}_{T}=\frac{\tilde{r}_{T}}{\left(s-s_{0}\right)}=\frac{\left(s-s_{1}\right)}{\left(s-s_{0}\right)} \tilde{g}_{1}^{*} k_{t}^{2} d / d_{F}
$$

This contribution to the projectile angular deviation is not constant with respect to range except for cases when $s_{l}$ is close to $s_{0}$ and $s$ is comparatively large, or in the limit as $s$ approaches infinity. Therefore, down range from the location where a lateral course correction is applied, the angular deviation of the projectile relative to the muzzle is not likely to be equal to the jump attributable to the tank launch event.

The fourth term, denoted $\tilde{r}_{L}$, is the lateral displacement attributable to all aerodynamic lift effects, i.e.,

$$
\tilde{r}_{L}=C_{L \alpha}^{*} \int_{s_{0}}^{s} \int_{s_{0}}^{\dot{r}_{2}} \widetilde{\xi} d r_{1} d r_{2}
$$

Upon performing the double integration, it becomes apparent that the lift terms can be separated into the sum of two specific complex terms, i.e.,

$$
\tilde{r}_{L}=\tilde{r}_{E}+\tilde{r}_{A}
$$

The epicyclic component of the swerve, $\tilde{r}_{E}$, can be algebraically simplified and expressed in terms of the motion parameters and aerodynamic coefficients in the first interval as

$$
\tilde{r}_{E}=k_{t}^{2} \frac{C_{L \alpha}}{C_{M \alpha}}\left(\tilde{\xi}-\tilde{\xi}_{0}-\tilde{\xi}_{l}^{*}\right)
$$


The epicyclic component of the swerve is the only component that fluctuates with respect to range. The magnitude of the epicyclic component for the idealized projectile with small yaws of the current study remains on the order of the projectile diameter. It is therefore not considered to be a significant contributor to lateral displacement, given the current assumptions.

The remaining aerodynamic lift terms can be collected and simplified in the first interval as

$$
\tilde{r}_{A}=-k_{t}^{2} \frac{C_{L \alpha}}{C_{M \alpha}}\left[\left(s-s_{0}\right) \tilde{\xi}_{0}^{\prime}+\left(s-s_{1}\right) \tilde{g}_{1}^{*}\right]
$$

This term's contribution to the projectile angular deviation at range $\left(s-s_{0}\right)$ is denoted here as $\tilde{\theta}_{A}$ and is

$$
\tilde{\theta}_{A}=\frac{\tilde{r}_{A}}{\left(s-s_{0}\right)}=-k_{t}^{2} \frac{C_{L \alpha}}{C_{M \alpha}}\left[\tilde{\xi}_{0}^{\prime}+\frac{\left(s-s_{1}\right)}{\left(s-s_{0}\right)} \tilde{g}_{1}^{*}\right]
$$

In Equation (65), the contribution from the initial projectile angular rate $\left(\tilde{\xi}_{0}^{\prime}\right)$ is recognizable as the aerodynamic jump as expressed by Murphy (1963) and McCoy (1998) for a non-spinning, statically stable projectile. It can be concluded from Equation (65) that, down range from the location where a lateral course correction is applied, the total aerodynamic contribution to angular deviation is not likely to equal the aerodynamic jump attributable to the tank launch event. The expression does, however, demonstrate the equivalency that exists between the angular impulse imparted to the projectile by the gun and the angular impulse imparted by the applied in-flight angular impulse. If the applied angular impulse occurs close to the muzzle in comparison to the target range, the expression can be approximated as

$$
\tilde{\theta}_{A}=-k_{t}^{2} \frac{C_{L \alpha}}{C_{M \alpha}}\left(\tilde{\xi}_{0}^{\prime}+\tilde{\eta}_{1}^{*}\right)
$$

\section{ANGULAR MOTION WITH SQUARE IMPULSE}

If the applied lateral translational and angular disturbances are modeled as square wave disturbances with non-zero duration, as described earlier, then Equation (21) can be written as

$$
\tilde{\xi}^{\prime \prime}-M \tilde{\xi}=\tilde{g}_{1}^{*}\left[h\left(s-s_{1}+\Delta s_{1}\right)-h\left(s-s_{1}\right)\right]-\tilde{\xi}_{1}^{*}\left[h^{\prime}\left(s-s_{1}+\Delta s_{1}\right)-h^{\prime}\left(s-s_{1}\right)\right]
$$


The general solution, with the simplification that $\phi^{\prime}=\phi_{1, n}^{\prime}=-\phi_{2, n}^{\prime}$, is

$$
\begin{aligned}
& \tilde{\xi}=K_{1,0} e^{i \phi_{1,0}} e^{i \phi_{1,0}^{\prime}\left(s-s_{0}\right)}+K_{2,0} e^{i \phi_{2,0}} e^{i \phi_{2,0}^{\prime}\left(s-s_{0}\right)} \\
& -\frac{\tilde{g}_{1}^{*}}{2 \phi^{\prime 2}}\left[h\left(s-s_{1}+\Delta s_{1}\right)\left(e^{i \phi^{\prime}\left(s-s_{l}+\Delta s_{l}\right)}+e^{-i \phi^{\prime}\left(s-s_{l}+\Delta s_{l}\right)}-2\right)\right. \\
& \left.-h\left(s-s_{l}\right)\left(e^{i \phi^{\prime}\left(s-s_{l}\right)}+e^{-i \phi^{\prime}\left(s-s_{l}\right)}-2\right)\right] \\
& +\frac{i \tilde{\xi}_{l}^{*}}{2 \phi^{\prime}}\left[h\left(s-s_{l}+\Delta s_{l}\right)\left(e^{i \phi^{\prime}\left(s-s_{l}+\Delta s_{l}\right)}-e^{-i \phi^{\prime}\left(s-s_{l}+\Delta s_{1}\right)}\right)\right. \\
& \left.-h\left(s-s_{l}\right)\left(e^{i \phi^{\prime}\left(s-s_{l}\right)}-e^{-i \phi^{\prime}\left(s-s_{l}\right)}\right)\right]
\end{aligned}
$$

The solution in the $n t h$ interval can be written in modal form as

$$
\tilde{\xi}=K_{1, n} e^{i \phi_{1, n}} e^{i \phi^{\prime}\left(s-s_{0}\right)}+K_{2, n} e^{i \phi_{2, n}} e^{i \phi^{\prime}\left(s-s_{0}\right)}
$$

although this particular form does not apply within the sub-interval itself. While the modal form for the square impulse is the same as for the singular impulse, the values of the modal parameters themselves (with the exception of $\phi^{\prime}$ ) are different. The expressions relating the modal parameters of adjacent intervals, however, are not needed to solve the swerve equation for the square impulse model and are not included here. It will be shown that, for the conditions of interest here, the square impulse model gives only slightly modified expressions as the singular impulse model for the projectile lateral motion.

\section{TRANSLATIONAL MOTION WITH SQUARE IMPULSE}

The swerve equation for the square impulse model can be written as

$$
y^{\prime \prime}+i z^{\prime \prime}=C_{L \alpha}^{*} \tilde{\xi}+\frac{\tilde{\xi}_{1}^{*}}{\Delta s_{1}}\left[h\left(s-s_{1}+\Delta s_{1}\right)-h\left(s-s_{1}\right)\right]-g / m
$$

The functional form of the complex angle of attack $\tilde{\xi}$ on the right-hand side now contains the additional terms representing the effects of the square impulse on the angular motion, as given by Equation (68). The solution can be written in the same form as for the singular impulse, i.e., 


$$
\tilde{r}=\tilde{r}_{0}+\tilde{r}_{0}^{\prime}\left(s-s_{0}\right)+\tilde{r}_{T}+\tilde{r}_{L}
$$

The terms $\tilde{r}_{0}$ and $\tilde{r}_{0}^{\prime}\left(s-s_{0}\right)$ are unchanged from the singular impulse model. The nonaerodynamic component of the lateral displacement attributable to the translational impulse is now

$$
\tilde{r}_{T}=\int_{s_{0}}^{s} \int_{s_{0}}^{r_{2}} \frac{\tilde{\xi}_{1}^{*}}{\Delta s_{1}}\left[h\left(s-s_{1}+\Delta s_{1}\right)-h\left(s-s_{1}\right)\right] d r_{1} d r_{2}
$$

and is evaluated in the first interval as

$$
\tilde{r}_{T}=\left(s-s_{1}\right) \tilde{\xi}_{1}^{*}+1 / 2 \Delta s_{1} \tilde{\xi}_{1}^{*}
$$

The first term on the right-hand side of this expression is identical to that of the singular impulse model. The second term is the difference between the square and singular impulse models for this component of the swerve and is denoted $\Delta \tilde{r}_{T}$ and given as

$$
\Delta \tilde{r}_{T}=1 / 2 \Delta s_{1} \tilde{F}_{1}^{*}
$$

As in the singular impulse case, the lateral displacement attributable to aerodynamic lift, $\tilde{r}_{T}$, can be separated into components $\tilde{r}_{E}$ and $\tilde{r}_{A}$. The epicyclic swerve component, $\tilde{r}_{E}$, for the square impulse model differs slightly from that of the singular impulse model. However, like the singular impulse model, its magnitude is still small and is not considered to be a significant contributor to the projectile angular deviation during the current conditions.

The remaining lift terms can be collected and simplified to express $\tilde{r}_{A}$ in the first interval as

$$
\tilde{r}_{A}=-k_{r}^{2} \frac{C_{L \alpha}}{C_{M \alpha}}\left[\left(s-s_{0}\right) \tilde{\xi}_{0}^{\prime}+\left(s-s_{1}\right) \tilde{g}_{1}^{*}+1 / 2 \Delta s_{1} \tilde{g}_{1}^{*}\right]
$$

which is the same as for the singular impulse model but with an additional term representing the difference between the square and singular impulse models for this component of the swerve which is denoted $\Delta \widetilde{r}_{A}$ and given as

$$
\Delta \widetilde{r}_{A}=-1 / 2 k_{t}^{2} \frac{C_{L \alpha}}{C_{M \alpha}} \Delta s_{1} \tilde{g}_{1}^{*}
$$




\section{RESULTS}

\subsection{Case 1: No Impulse}

The numerical trajectory simulation code written by Costello (1997) was used in 6-DOF mode to validate the analytical theory. Many different cases with varying launch conditions and in-flight lateral impulses were examined during the course of the study, but only three cases are presented here. The idealized projectile configuration was introduced earlier in the report. For all three cases to be presented, the launch velocity is prescribed to be $1600 \mathrm{~m} / \mathrm{s}$ (approximately Mach 4.7). The gun elevation is prescribed to be zero, i.e., horizontal to the ground. The projectile is prescribed to exit the gun with no lateral translational rate relative to the pre-trigger line of fire, i.e., the components of $\tilde{r}_{0}^{\prime}$ are zero in both azimuth and elevation. The pitch and yaw angles are prescribed to be zero at launch. The projectile is non-spinning.

In Case 1, no in-flight lateral impulse is applied. While the existing theory of epicyclic motion as described by Murphy (1963) and McCoy (1998) is adequate to handle this case, some defining characteristics of the projectile motion can be extracted with which to compare subsequent cases. The initial angular rate is prescribed to be $5 \mathrm{rad} / \mathrm{s}$, with the nose rotating directly upward. The angular motion is planar and sinusoidal, occurring strictly in the vertical $(\alpha)$ plane. Figure 7 shows the numerical and analytical results for pitch angle versus range from launch to $1 \mathrm{~km}$ range. The maximum pitch angle is approximately $2.9^{\circ}$. Because no damping is used in either the analytical or numerical models, the amplitude of the sinusoidal motion remains constant throughout the flight.

Figure 8 shows the lateral displacement versus range from the numerical and analytical methods for Case 1 from launch to $3 \mathrm{~km}$ range. Like the angular motion, the translational motion is planar, occurring strictly in the vertical plane. The numerical and analytical results for Case 1 are indistinguishable in Figure 8. The vertical displacement from the two approaches is approximately $1.478 \mathrm{~m}$ upward at $3 \mathrm{~km}$ range, and the two methods differ by less than $1 \mathrm{~mm}$. The fluctuating component of the swerve is seen to be small (on the order of a few centimeters) compared to the total swerve, indicating that a good estimate of lateral displacement can be obtained even if that component is ignored. 


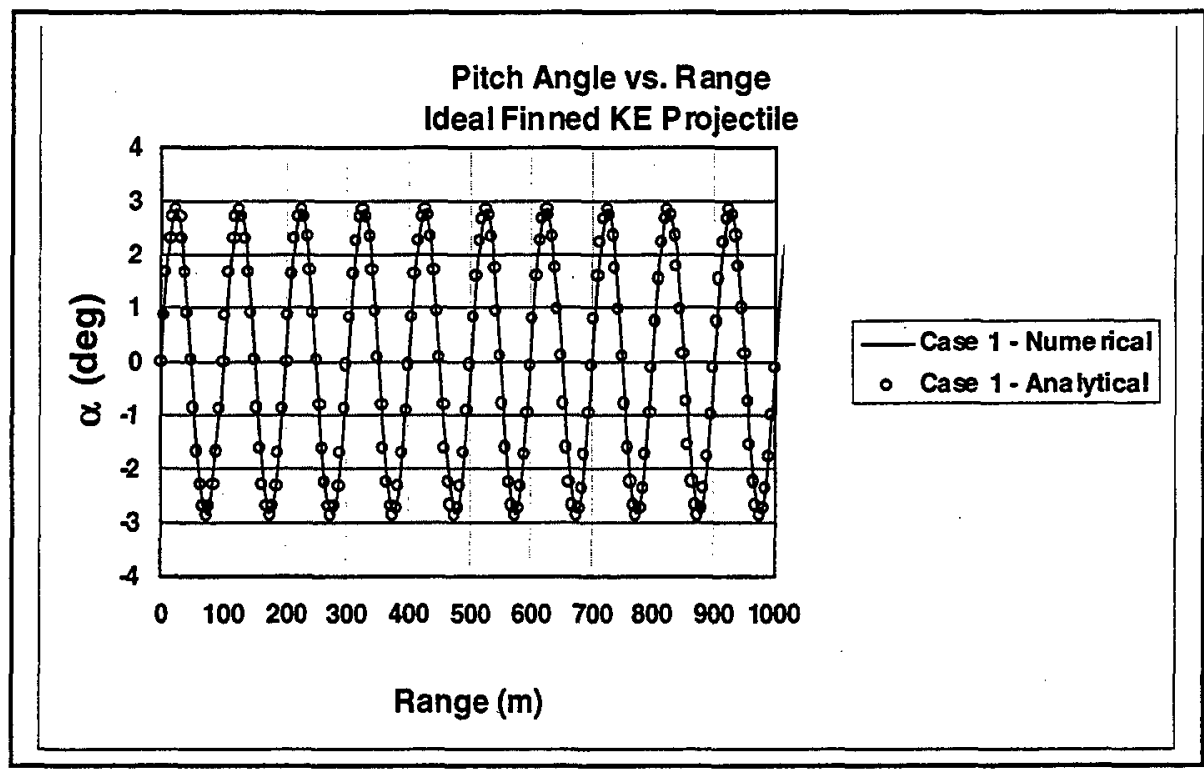

Figure 7. Pitch Angle Versus Range, Case 1.

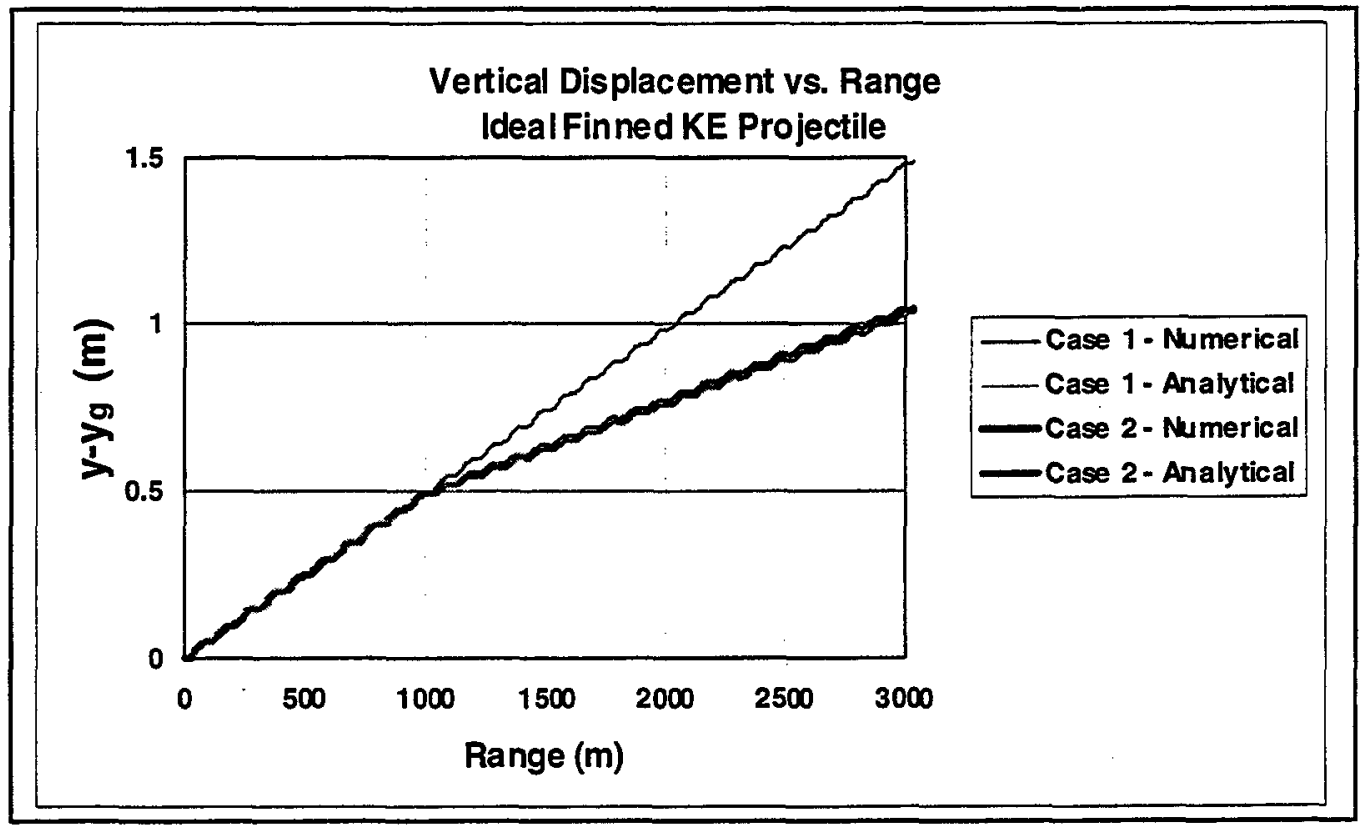

Figure 8. Vertical Displacement Versus Range, Cases 1 and 2.

\subsection{Case 2: In-Plane Impulse}

Case 2 is the same as Case 1, except that the lateral jet is engaged at some location in midflight. As was shown in Table 1, the jet is located $0.2 \mathrm{~m}$ in front of the CG and the magnitude of the impulse is $1 \mathrm{~N}$-s. The orientation of the jet relative to the ground is such that the jet releases 
upward, resulting in a downward force applied to the projectile nose, (i.e., $\phi_{I}=0^{\circ}$ ). The jet (i.e., impulse) therefore acts within the vertical plane of motion to which the projectile is already adhering. In the analytical case, the impulse is modeled as a singular impulse occurring at $992 \mathrm{~m}$ range. In the numerical case, the impulse is modeled as a square wave disturbance initiated at $0.615 \mathrm{~s}$ into the flight (corresponding to $984 \mathrm{~m}$ range) with a duration of $10 \mathrm{~ms}$ (i.e., occurring over a range of approximately $16 \mathrm{~m}$ ). The resulting angular and translational motions for Case 2, as for Case 1, are planar motions occurring strictly in the vertical plane.

The vertical displacement obtained from the analytical and numerical approaches is included in Figure 8, along with the result from Case 1. The vertical displacement is calculated by the analytical theory to be $1.029 \mathrm{~m}$ at $3 \mathrm{~km}$ range, almost 0.5 meter below the vertical displacement of Case 1. The analytical and numerical results are indistinguishable in the figure, although the two methods give results that differ by approximately $1 \mathrm{~cm}$. It was found that this difference was a function of the time step size used in the numerical trajectory simulation code and could be reduced with a further reduction in the time step size. The time step size apparently affected the numerical integration process near the beginning and end of the square wave disturbance. The numerical result shown here used a time step size equal to $0.25 \mathrm{~ms}$.

The analytical result could be generated using the square wave impulse model rather than the singular impulse model, but the results would be virtually unchanged. The difference between the square wave and singular impulse analytical models of the non-aerodynamic lateral displacement component, $\Delta \widetilde{r}_{T}$, is calculated using Equation (74) to be 0.0394 caliber, or approximately $1 \mathrm{~mm}$. The difference in the aerodynamic component, $\Delta \tilde{r}_{A}$, is calculated using Equation (76) to be 0.005 caliber, or approximately $0.13 \mathrm{~mm}$. Both of these differences are independent of range. It is concluded that for Case 2, the difference between the lateral displacement calculated by the singular impulse model and the square impulse model is insignificant. A substantial increase in either the impulse magnitude or the impulse duration would be required before the differences between the singular impulse model and the square impulse model become significant. 
The analytical result of Case 2 shows that the applied impulse causes a lateral course correction of $0.437 \mathrm{~m}$ downward from the uncorrected flight of Case 1. Equations (59) and (64) can be used to show that the translational (i.e., non-aerodynamic) component provides $56 \%$ of the lateral course correction, while the angular (i.e., aerodynamic) component provides the remaining $44 \%$.

Figure 9 shows the pitch angle as a function of range for Cases 1 and 2 as obtained from the analytical and numerical approaches. The figure shows the detailed behavior of the pitch angle at and near the range at which the lateral jet impulse is applied. While no strict quantitative characterization is made between the analytical and numerical results, both the amplitude and phase of the sinusoidal motions appear qualitatively correct to within the scale of the figure. The application of the jet impulse produces a slight shift in phase as well as a decrease of maximum pitch angle of approximately $0.5^{\circ}$.

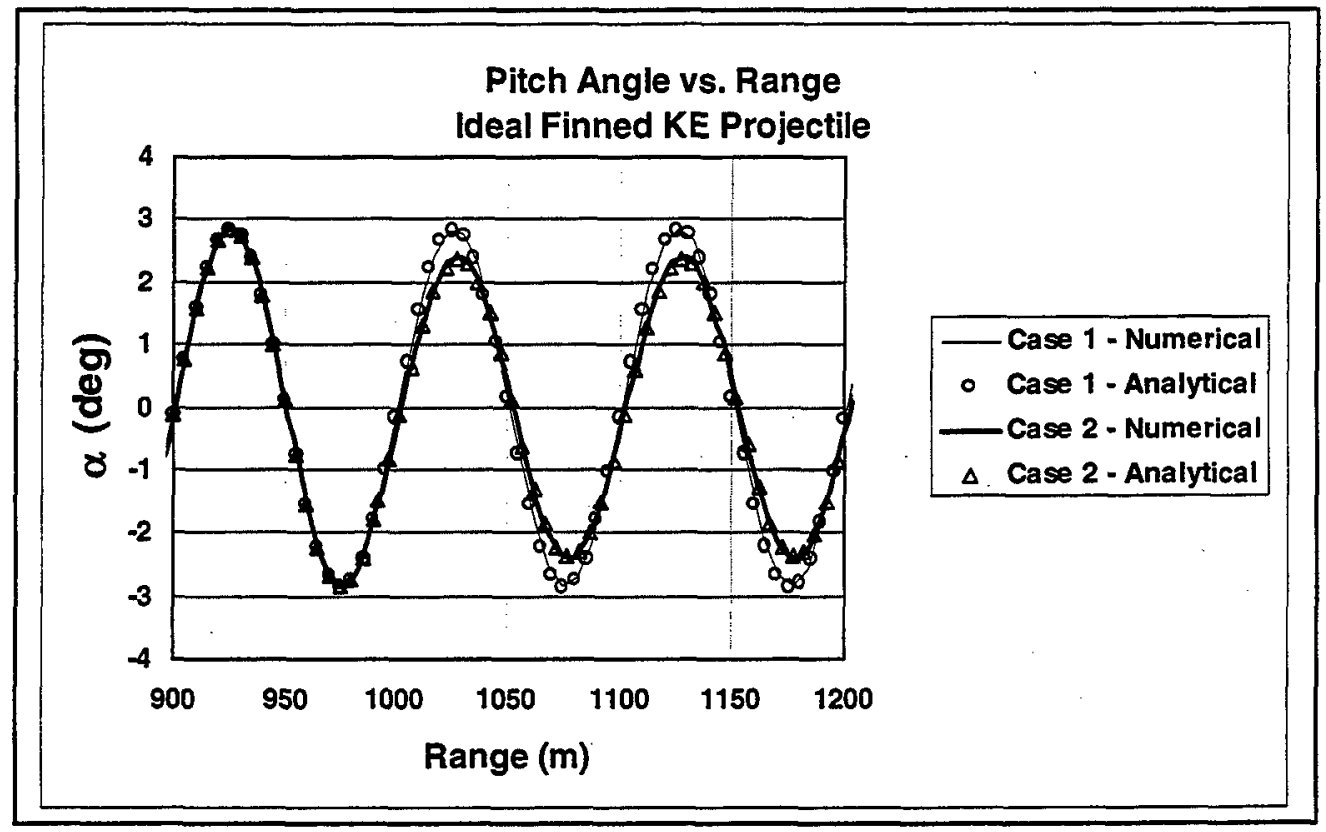

Figure 9. Pitch Angle Versus Range, Cases 1 and 2.

In general, the change in maximum angle of attack produced by the lateral jet can be positive or negative, depending upon where in the yaw cycle the impulse is applied. The analytical theory has the ability to characterize the pitching and yawing behavior in closed form in this manner, although no further discussion is made of this aspect at this time. It is noted that 
a more advanced application of the analytical theory is the simultaneous control of lateral displacement and angular behavior. Such an approach leads to the design of guidance maneuvers that not only improve accuracy but also reduce the in-flight maximum angle of attack.

\subsection{Case 3: Out-of-Plane Impulse}

Case 3 is the same as Case 2 except that the orientation of the jet is such that the jet releases to the gunner's left, resulting in the projectile nose being forced to the gunner's right (i.e., $\phi_{1}=90^{\circ}$ ). That is, a horizontal impulse is applied out of the plane of the existing vertical motion. The resulting angular and translational motions are no longer limited to the vertical plane. Figure 10 shows the analytical and numerical results of the vertical displacement for Case 3. The results are plotted with those from Case 1, and all four lines are indistinguishable, demonstrating that the vertical translational motion is unaffected by the horizontal impulsive disturbance.

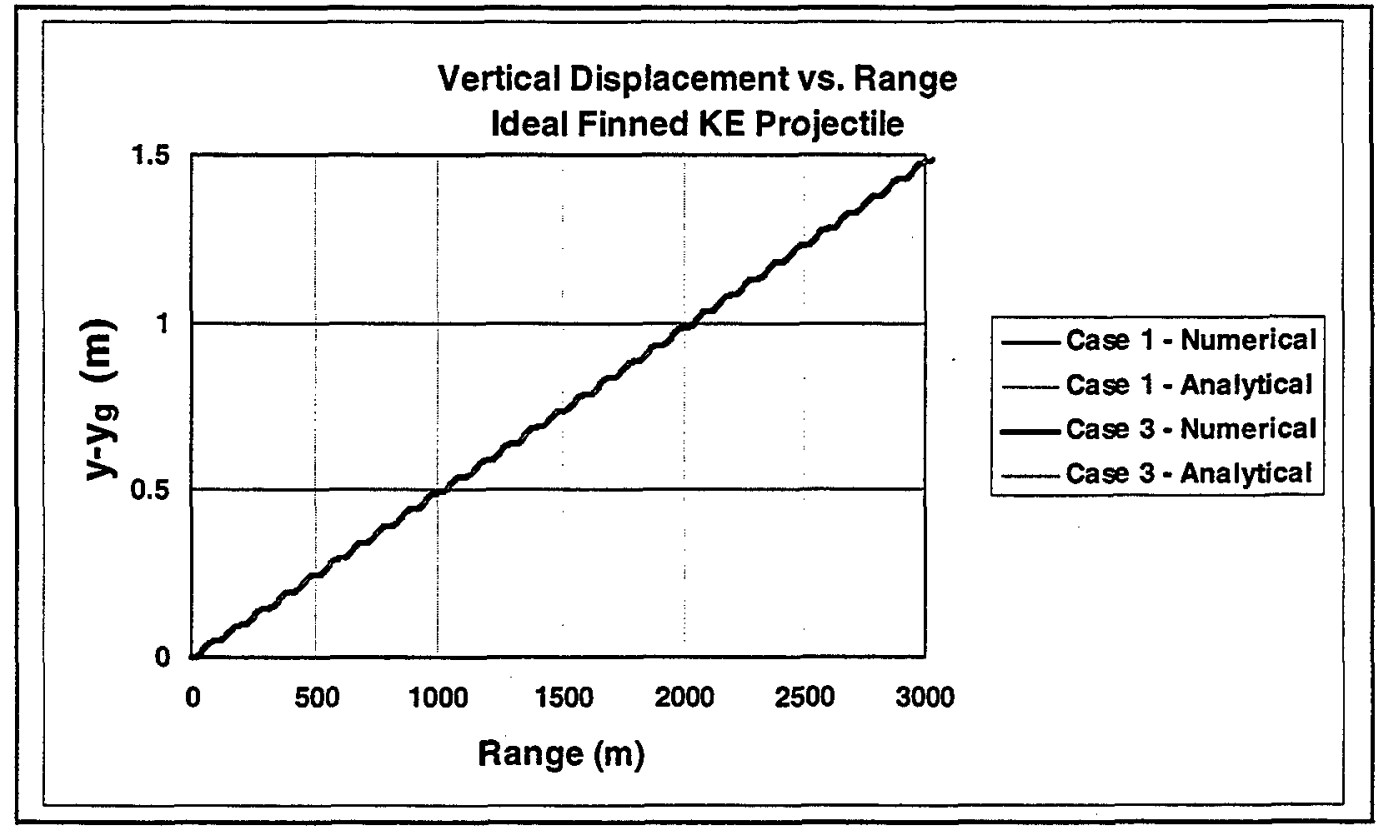

Figure 10. Vertical Displacement Versus Range, Cases 1 and 3.

Figure 11 shows the analytical and numerical results of horizontal displacement for Case 3 , along with the results from Case 1. Up range from the range at which the jet is initiated, the horizontal displacement is zero for both cases. For Case 3, however, the impulse produces a 
horizontal displacement to the gunner's right, while the horizontal displacement for Case 1 remains zero throughout the flight. The horizontal displacement for Case 3 is equal in magnitude to that of the vertical course correction observed in Case 2. Also, as in Case 2, the difference between the analytical and numerical result is approximately $1 \mathrm{~cm}$ at $3 \mathrm{~km}$ range and is attributable to a numerical integration error that is affected by the time step size.

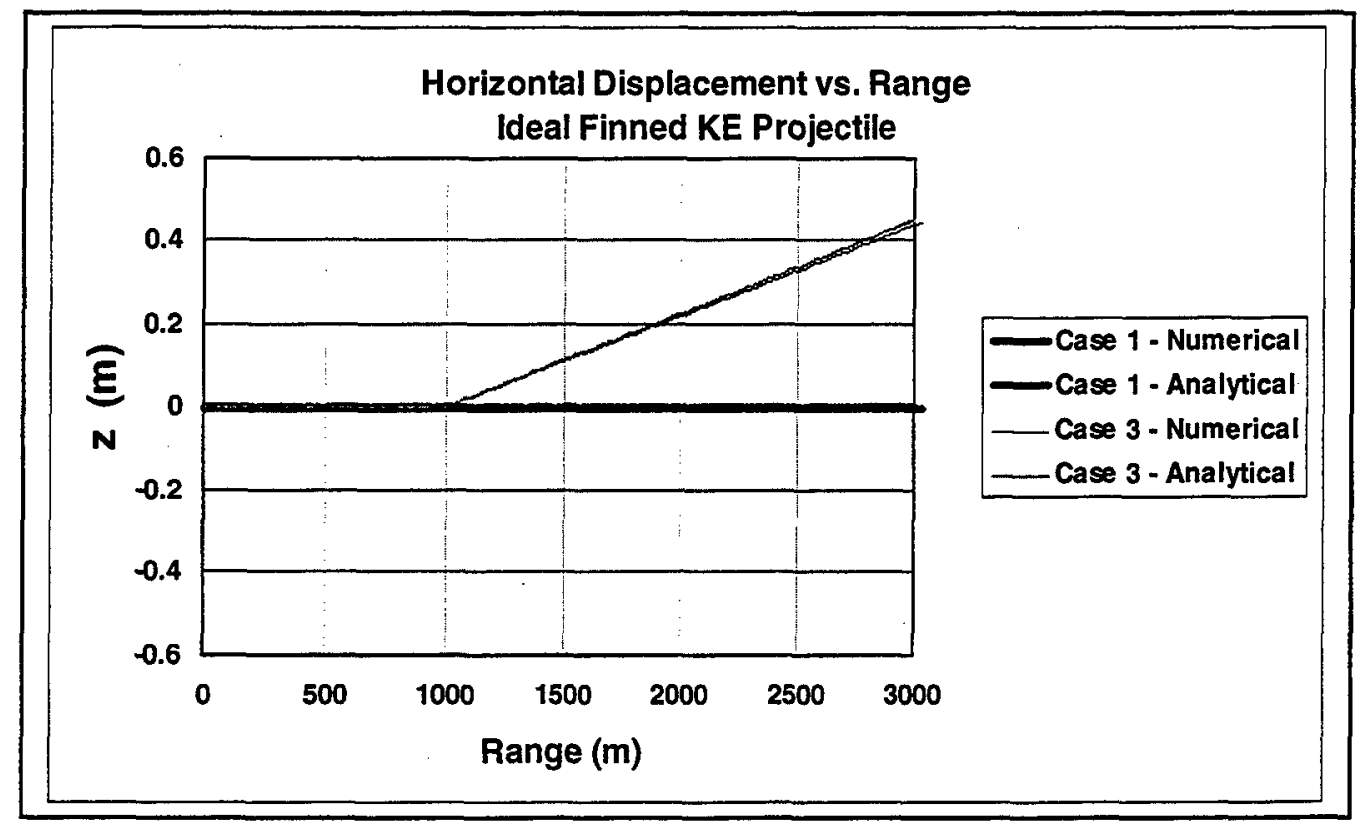

Figure 11. Horizontal Displacement Versus Range, Cases 1 and 3.

Finally, Figure 12 shows the analytical and numerical results of the angular motion for Case 3. As in Figure 9, the figure shows the detailed behavior near the range at which the lateral jet impulse is applied. The pitching motion is unaffected by the lateral jet but the yawing motion, however, is affected. Up range from the range at which the lateral jet is applied, the yaw angle is equal to zero. The impulse produces yawing motion that reaches a maximum value greater than $0.5^{\circ}$. The analytical and numerical results compare qualitatively to within the scale of the figure. It is concluded here that the analytical theory has been validated by the numerical approach for all three cases for both angular and translational motion with the prescribed conditions. 


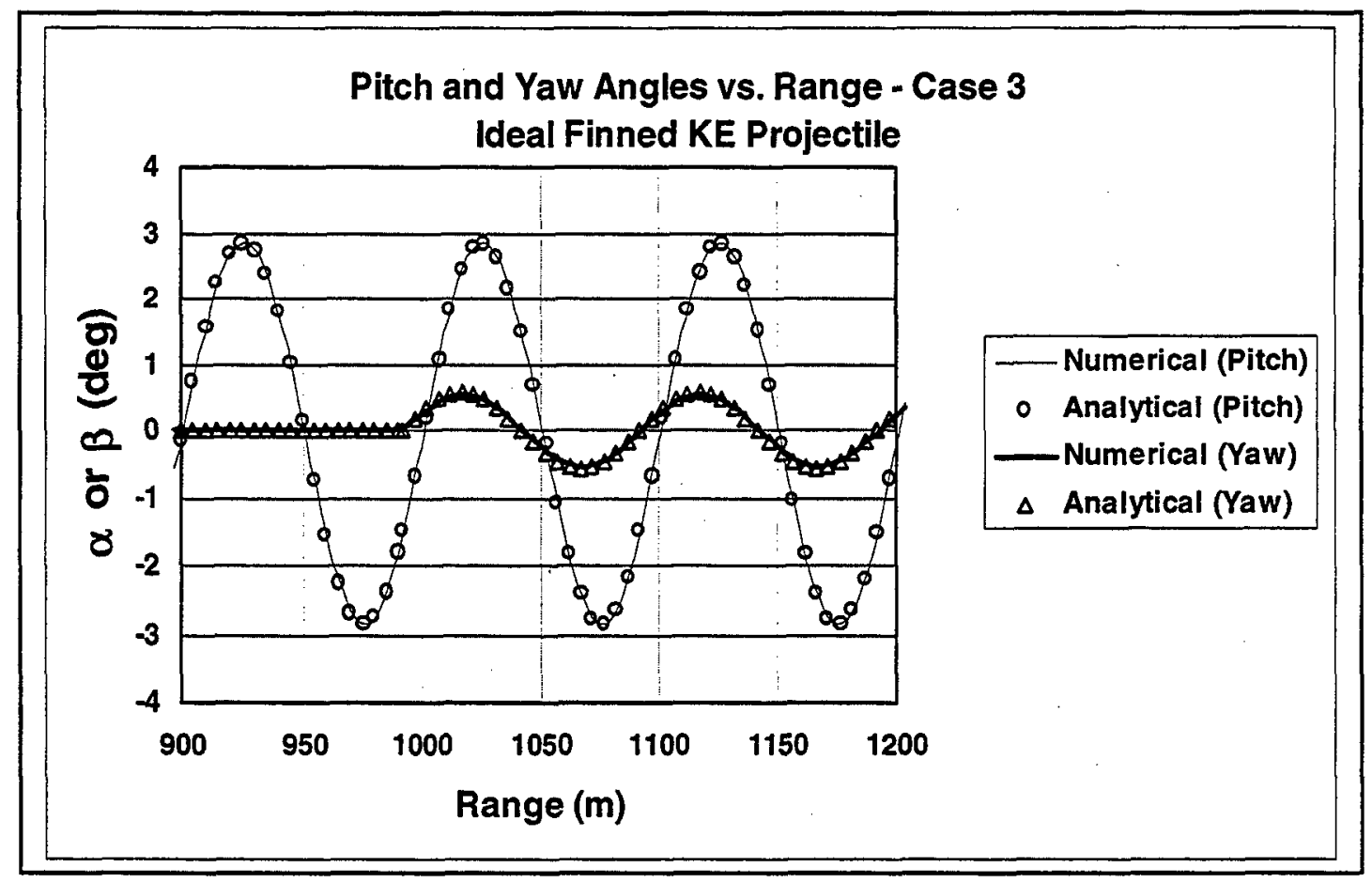

Figure 12. Pitch and Yaw Angles Versus Range, Case 3.

\section{CONCLUSION}

An analytical theory for quantifying the effect of a simple in-flight impulsive disturbance acting on a non-spinning KE projectile has been presented. The theory is based on the incorporation of a specific class of modeled applied lateral translational and angular impulsive disturbances into the equations of projectile free-flight motion. The modified equations were solved to obtain the angular and translational motion of the projectile, and the components of the translational motion were extracted.

A sample of results from the analytical model was validated by an existing numerical trajectory simulation code. The lateral impulse simulated a constant magnitude, constant direction, 1-N-s lateral jet with a duration of $10 \mathrm{~ms}$, located on the nose of the projectile and initiated at a range of $1 \mathrm{~km}$. The calculated lateral displacement of the projectile, as well as the components of the displacement, consistently agreed with the numerical results to approximately $1 \mathrm{~cm}$ at $3 \mathrm{~km}$ range. The difference was found to be caused by error associated with the time step 
size in the numerical code. Both sets of results showed that the lateral course correction maneuver produced a lateral displacement of almost 0.5 meter at $3 \mathrm{~km}$ range.

Two different analytical models for the applied impulsive disturbances were presented: a singular impulse model and a square impulse model. For the impulse magnitude and duration of the prescribed jet, insignificant differences were found between the two models. It was concluded that a substantial increase in the magnitude and/or duration of the square wave impulse would be necessary before the difference in lateral displacement between the two models would be significant. The consideration is relevant because the singular impulse is a convenient form with which to model actual impulsive disturbances.

The analytical model provides closed form analytical solutions to the equations of angular and translational motion for a projectile acted upon by this specific class of generalized impulsive disturbances. While the lengthy mathematics of the solution procedure have been omitted from the report, the final expressions are simple and straightforward. The simplicity of the expressions suggests that reduced computational overhead for on-board course correction instrumentation may be achievable. Furthermore, the theory has application in the testing and development of smart munitions, providing a framework for analyzing and predicting free-flight motion of a projectile undergoing applied course correction maneuvers.

The impulse model was presented here for non-rolling, statically stable projectiles, neglecting pitch damping. Typically, KE projectiles are adequately damped and have low to moderate spin rates. The generalization to include these parameters is a straightforward extension of the current theory. In addition, the complete incorporation of the translational impulse into the angular equations will be necessary to accommodate certain classes of larger impulsive disturbances.

One of the most important extensions of the current theory, however, is the incorporation of successive disturbances in order to facilitate the modeling of highly complex motions and course correction maneuvers. An example of such a maneuver is one in which a multi-stage course correction is derived that improves the accuracy of the projectile while simultaneously reducing its maximum angle of attack. 
INTENTIONALLY LEFT BLANK 


\section{REFERENCES}

Cooper, G., and K. Fansler, "Yaw Card Perturbation of Projectile Dynamics," ARL-TR-1258, U.S. Army Research Laboratory, Aberdeen Proving Ground, Maryland, January 1997.

Costello, M.F., "Potential Field Artillery Projectile Improvement Using Movable Canards," ARL-TR-1344, U.S. Army Research Laboratory, Aberdeen Proving Ground, Maryland, April 1997.

Lighthill, M.J., Introduction to Fourier Analysis and Generalized Functions, New York: Cambridge University Press, 1958.

McCoy, R.L, Modern Exterior Ballistics, Schiffer Publishing Ltd., Atglen, PA, 1998.

Murphy, C.H., "Free Flight Motion of Symmetric Missiles," BRL-R-1216, U.S. Army Ballistic Research Laboratories, Aberdeen Proving Ground, Maryland, July 1963. 
INTENTIONALLY LEFT BLANK 
APPENDIX A

LIST OF SYMBOLS 
INTENTIONALLY LEFT BLANK 


\section{LIST OF SYMBOLS}

$A$

d

$d_{F}$

$C_{L \alpha}$

$C_{M \alpha}$

$\tilde{C}_{M I}$

$\tilde{C}_{N I}$

$\vec{F}_{I}$

$\tilde{\xi}_{1}^{*}$

$g$

$h$

$I_{t}$

$\bar{I}, \bar{J}, \bar{K}$

$\bar{i}, \bar{j}, \bar{k}$

$\tilde{g}_{1}^{*}$

$K_{j, n}$

$\tilde{\bar{k}}_{j, n}$

$k_{t}$

$\vec{M}_{1}$

$\tilde{\mathbb{M}}_{1}^{*}$

$m$

$\tilde{r}$

$\tilde{r}_{A}$

$\tilde{r}_{E}$

$\tilde{r}_{L}$

reference area, $\pi d^{2} / 4$

reference diameter

distance from CG to location of applied force, negative if applied aft of CG

lift force coefficient

pitching moment coefficient

complex nondimensional applied moment coefficient

complex nondimensional applied lateral force coefficient

applied translational disturbance vector

complex nondimensional applied translational impulse

gravitational constant

unit step function

transverse moment of inertia

earth-fixed Cartesian coordinate system unit vectors

non-rolling coordinate system unit vectors aligned with projectile velocity vector

complex applied angular impulse quantity, $\tilde{\mathscr{M}}_{1}^{*} / k_{t}^{2}$

magnitude of $j$ th complex modal arm in $n$th interval

$j$ th complex reference modal arm in $n$th interval

radius of gyration

applied angular disturbance vector

complex nondimensional applied angular impulse

projectile mass

complex lateral displacement

non-fluctuating complex lateral displacement attributable to aerodynamic effects

fluctuating complex lateral displacement attributable to aerodynamic effects

complex lateral displacement attributable to all aerodynamic effects 
$\tilde{r}_{T} \quad$ complex lateral displacement attributable to translational component of applied disturbance

distance along flight path

$t$

time

projectile velocity vector

$\checkmark$

magnitude of projectile velocity vector

$X, Y, Z \quad$ earth-fixed coordinates

$\bar{x}, \bar{y}, \bar{z} \quad$ rolling body-fixed coordinate system unit vectors

$x, y, z \quad$ earth-fixed coordinates normalized by projectile reference diameter

\section{Greek Symbols}

$\alpha \quad$ pitch angle

$\beta \quad$ yaw angle

$\widetilde{\xi} \quad$ complex yaw angle, $\alpha+i \beta$

$\delta \quad$ Dirac delta function

$\tilde{\theta} \quad$ complex angular deviation relative to gun muzzle

$\tilde{\theta}_{A} \quad$ non-fluctuating complex angular deviation attributable to aerodynamic effects

$\tilde{\theta}_{T} \quad$ complex angular deviation attributable to translational component of applied disturbance

$\phi_{n} \quad$ orientation of $n$th applied translational impulse

$\phi_{j, n} \quad j$ th reference phase angle in $n$th interval

$\phi_{j, n}^{\prime} \quad j$ th reference phase angle turning rate in $n$th interval

\section{Superscipts}

$q^{\prime} \quad$ derivative of quantity $q$ with respect to $s$

$q^{*}$ normalization of quantity $q$ by density factor, $\rho A d /(2 m)$ 


\section{Miscellaneous}

$\tilde{q} \quad$ complex representation of quantity $q$

$\vec{q} \quad$ vector representation of quantity $q$

$\bar{q} \quad$ unit vector $q$ 
INTENTIONALLY LEFT BLANK 
NO. OF

COPIES ORGANIZATION

1 ADMINISTRATOR

DEFENSE TECHNICAL INFO CENTER

ATTN DTIC OCP

8725 JOHN J KINGMAN RD STE 0944

FT BELVOIR VA 22060-6218

1 DIRECTOR

US ARMY RESEARCH LABORATORY

ATTN AMSRL CS AS REC MGMT

2800 POWDER MILL RD

ADELPHI MD 20783-1197

1 DIRECTOR

US ARMY RESEARCH LABORATORY

ATTN AMSRL CI LL TECH LIB

2800 POWDER MILL RD

ADELPHI MD 207830-1197

1. DIRECTOR

US ARMY RESEARCH LABORATORY

ATTN AMSRL DD

2800 POWDER MUL RD

ADELPHI MD 20783-1197

8 PROJECT MANAGER

TANK MAIN ARMAMENT SYSTEMS

ATTN SFAE GCSS TMA

R MORRIS C KIMKER

E KOPACZ R DARCY

D GUZIEWICZ P CARDELL

C CORDING R MCDANOLDS

PICATINNY ARSENAL NJ 07806-5000

1 COMMANDER

US ARMY TACOM ARDEC

ATTN SFAE GCSS ARMS R KOWALSKI

PICATINNY ARSENAL NJ 07806-5000

1 COMMANDER

US ARMY TACOM ARDEC

ATTN SFAE GCSS CR

R BILLINGTON

PICATINNY ARSENAL NJ $\quad 07806-5000$

5 CDR US ARMY TACOM ARDEC

ATTN AMSTA AR CCH A R CARR MLUCLANO A MUSALLI G KOLASA M PALATHINGAL PICATINNY ARSENAL NJ $\quad 07806-5000$
NO. OF

COPIES ORGANIZATION

2 COMMANDER

US ARMY TACOM ARDEC

ATTN AMSTA AR QAC

D RIGOGLIOSO R ROESER

PICATINNY ARSENAL NJ 07806-5000

18 CDR US ARMY TACOM ARDEC

ATTN AMSTA AR FSF T

CLIVECCHIA J GRAU

B WONG CNG

AFARINA GMALEJKO

SCHUNG E VAZQUEZ

S HAN H HUDGINS

W TOLEDO L YEE

$D$ PEDERSEN R TROHANOWSKY

A FIORELLINI J THOMASOVICH M AMORUSO J MURNANE

PICATINNY ARSENAL NJ 07806-5000

3

COMMANDER

US ARMY TACOM ARDEC

ATTN AMSTA AR FSF D

K PFLEGER R TESTA

ELA ROSA

PICATINNY ARSENAL NJ $07806-5000$

5 COMMANDER

US ARMY TACOM ARDEC

ATTN AMSTA AR CCH B R SAYER

FCHANG GEUSTICE

S PATEL G WAGNECZ

PICATINNY ARSENAL NJ $07806-5000$

7 CDR US ARMY TACOM

ATTN SFAE GCSS W COL J MORAN LTC S COOPER LTC R GROLLER J NEFF J FLECK S GOODMAN J FLORENCE

WARRENMI 48397-5000

1 DIRECTOR

US ARMY ARMOR CTR

ATTN ATZK TD A POMEY

FT KNOX KY 40121

1 DIRECTOR

US ARMY ARMOR CTR

ATTN ATZK TS W MEINSHAUSEN

FT KNOX KY 40121 
NO. OF

COPIES ORGANIZATION

7 CDR US ARMY MICOM

ATTN AMSAM RDPS J COCHRAN

AMSMI RD ST P JACOBS

P RUFFIN W WALKER

AMSMI RD ST T VANDIVER

D DAVIS

AMSMI RD MG CLEWIS

C ROBERTS

REDSTONE ARSENAL AL 35898-5247

2 DIRECTOR HQ IOC

ATIN AMSIO SMT W HARRIS

M RIVERS

ROCK ISLAND IL 61299-6000

3 DIRECTOR

BENET LABORATORIES

ATTN AMSTA AR CCB J VASILAKIS

WATERVLIET NY 12189 R HASENBEIN GPFLEGL

9 AIR FORCE RESEARCH LAB

ATTN AAC/MN SLEFSTAD

$R$ WEHLING R JONES

T GRADY GABATE

M DEILER JWISE

R ZACHERY G WINCHENBACH

101 W EGLIN BLVD STE 219

EGLIN AFB FL 32542

6 AIR FORCE RESEARCH LAB

ATTN AAC / YV (JASSM)

T LITTLE J FELICI

S BROOKS D BRIDGES

R KIRBY T MCCOOL

102 WEST D AVE

EGLIN AFB FL 32542

1 NAVAL AIR WARFARE CTR

ATTN W GUNTHER

ONE ADMINISTRATION CIRCLE

473500D

CHINA LAKE CA 93555-6100

1 NAT GROUND INTEL CTR

ATTN J MORGAN

2207 TH ST NE

CHARLOTTESVILLE VA 22902-5396
NO. OF

COPIES ORGANIZATION

1 INST FOR ADVANCED TECHNOLOGY UNIV OF TEXAS AT AUSTIN

ATTN W REINECKE

4030-2 W BRAKER LANE

AUSTIN TX 78759-5329

1 OREGON STATE UNIVERSITY

DEP MECHANICAL ENGINEERING

ATTN M COSTELLO

CORVALLIS OR 97331

2 US MILITARY ACADEMY

DEP MATHEMATICAL SCIENCES

ATTN M GRAHAM

WEST POINT NY 10996-1786

5 UNIV OF CINCINNATI

DEP AEROSPACE ENGINEERING \& ENGINEERING MECHANICS

ATTN G SLATER S RUBIN

K GHIA PORKWIS

P KHOSLA

CINCINNATI OH 45221

1 SVERDRUP TECHNOLOGY INC

ATTN G MOLVIK

1099 AVE C

ARNOLD AFB TN 37389-9013

6 ALLIANT TECHSYSTEMS

ATTN C AAKHUS RBECKER RDOHRN CCANDLAND J GILES M JANTSCHER

600 2ND ST NE

HOPKINS MN 55343-8367

2 PRIMEX CORPORATION ATTN D OSMENT E STEINER

PO BOX 127

RED LION PA 17356

3 PRIMEX CORPORATION

ATTN L WHITMORE W PERKINS T NEAVES

$101019 T H$ ST NORTH

ST PETERSBURG FL 33702

4 ARROW TECH ASSOCIATES

ATTN R WHYTE W HATHAWAY

A HATHAWAY JWHYTE

1233 SHELBURNE RD SUTTE D-8

SOUTH BURLINGTON VT 05403 
NO. OF

COPIES

3 CHARLES STARK DRAPER LAB INC ATTN P ZARCHAN JDOWDLE K FLUECKIGER 555 TECHNOLOGY SQUARE CAMBRIDGE MA 02139-3563

1 ORION INTERNATIONAL ATTN M FLYNN

PO BOX 130

WHITE SANDS MISS RANGE NM 88002

ABERDEEN PROVING GROUND

2 DIRECTOR

ATTN AMSRL CI LP (TECH LIB)

BLDG 305

2 CDR USATEC

ATTN AMSTE TM S E KEELE J PIERSON

RYAN BLDG

5 COMMANDER

US ARMY ABERDEEN TEST CENTER

ATTN STEACFC R FRAILER $S$ HICKEY

STEAC SL S WALTON P MCCALL STEAC LI

BLDG 400

6 COMMANDER

US ARMY TACOM ARDEC

ATTN AMSTA AR FSF T RLIESKE J MATTS FMIRABELLE B TILGHMAN J WHITESIDE A SOWA

BLDG 120

2 DIRECTOR

US AMSAA

ATTN AMXSY CA R NORMAN

W YEAKEL

BLDG 367

1 DIR USARL

ATTN AMSRL WM B EM SCHMIDT BLDG 390A
NO. OF

COPIES ORGANZATION

10 DIR USARL ATTN AMSRL WM BA W D'AMICO FBRANDON TBROWN L BURKE B DAVIS T HARKINS D HEPNER MHOLLIS P MULLER A THOMPSON

BLDG 4600

21 DIR USARL

ATTN AMSRL WM BC P PLOSTINS

M BUNDY G COOPER

HEDGE TERLINE

J GARNER B GUIDOS (5 CYS)

KHEAVEY DLYON

A MIKHAIL J NEWILL

J SAHU K SOENCKSEN

DWEBB P WEINACHT

BLDG 390

$S$ WILKERSON A ZIELINSKI

2 DIR USARL

ATTN AMSRL WM MB W DRYSDALE C HOPPEL

BLDG 4600

2 DIR USARL

ATTN AMSRL WM TC R COATES

RMUDD

BLDG 309

ABSTRACT ONLY

1 DIRECTOR

US ARMY RESEARCH LABORATORY ATTN AMSRL EA TP (TECH PUBS) 2800 POWDER MILL RD

ADELPHI MD 207830-1197 
INTENTIONALLY LEFT BLANK 
Public reporting burden for this collection of information is estimated to average 1 hour per response, including the time for reviewing instructions, searching existing data sources, gathering and maintaining the data needed, and completing and reviewing the collection of information. Send comments regarding this burden estimate or any other aspect of this collection of information, including suggestions for reducing this burden, to Washington Headquarters Services, Directorate for Information Operations and Reports, 1215 Jefferson Davis Highway, Suite 1204, Arlington, VA 22202-4302, and to the Office of Management and Budget, Paperwork Reduction Project (0704-0188), Washington, DC 20503.

\begin{tabular}{|l|l|l|}
\hline 1. AGENCY USE ONLY (Leave blank) & $\begin{array}{c}\text { 2. REPORT DATE } \\
\text { December } 1999\end{array}$ & $\begin{array}{l}\text { 3. REPORT TYPE AND DATES COVERED } \\
\text { Final }\end{array}$ \\
\hline
\end{tabular}

4. TITLE AND SUBTITLE

5. FUNDING NUMBERS

The Effect of a Simple Lateral Impulse on Kinetic Energy Projectiles in Flight

6. AUTHOR(S)

Guidos, B.J.; Cooper, G.R. (both of ARL)

7. PERFORMING ORGANIZATION NAME(S) AND ADDRESS(ES)

8. PERFORMING ORGANIZATION REPORT NUMBER

U.S. Army Research Laboratory

Weapons \& Materials Research Directorate

Aberdeen Proving Ground, MD 21010-5066

9. SPONSORING/MONITORING AGENCY NAME(S) AND ADDRESS(ES)

U.S. Army Research Laboratory

Weapons \& Materials Research Directorate

Aberdeen Proving Ground, MD 21010-5066

Project No. 1L1622618.AH80

11. SUPPLEMENTARY NOTES

12a. DISTRIBUTION/AVAILABILITY STATEMENT

12b. DISTRIBUTION CODE

Approved for public release; distribution is unlimited.

\section{ABSTRACT (Maximum 200 words)}

Existing analytical theory for quantifying the free-flight motion of non-rolling, statically stable projectiles is extended to include the effect of a simple lateral impulse applied during flight. The extended theory is based on the incorporation of generalized lateral translational and angular disturbances into the familiar equations of projectile free-flight motion. The applied disturbances are then modeled using specified mathematical forms, and the modified equations are solved to obtain the angular and translational motion of the projectile over the trajectory. The various components of the translational motion of the projectile are extracted and characterized. An idealized application is presented for a large caliber finned projectile, representative of the class of 120 -mm long rod kinetic energy projectiles fired from the M1Al Abrams tank, subjected to a single lateral control impulse in flight. The analytical closed form solutions are validated against results obtained using a numerical trajectory simulation code that incorporates generalized guidance and control commands.

\begin{tabular}{|c|c|c|c|c|}
\hline \multirow{2}{*}{$\begin{array}{l}\text { 14. SUBJECT TERMS } \\
\text { course correction } \\
\text { flight dynamics }\end{array}$} & \multirow{2}{*}{\multicolumn{2}{|c|}{$\begin{array}{l}\text { guidance and control } \\
\text { kinetic energy projectile }\end{array}$}} & \multirow{2}{*}{$\begin{array}{l}\text { lateral jet } \\
\text { projectile dynamics }\end{array}$} & $\begin{array}{l}\text { 15. NUMBER OF PAGES } \\
50\end{array}$ \\
\hline & & & & 16. PRICE CODE \\
\hline \multicolumn{2}{|c|}{$\begin{array}{l}\text { 17. SECURITY CLASSIFICATION } \\
\text { OF REPORT }\end{array}$} & $\begin{array}{l}\text { 18. SECURITY CL } \\
\text { OF THIS PAGE }\end{array}$ & $\begin{array}{l}\text { 19. SECURITY CLASSIFICATION } \\
\text { OF ABSTRACT }\end{array}$ & 20. LIMITATION OF ABSTRACT \\
\hline \multicolumn{2}{|l|}{ Unclassified } & Unclassified & Unclassified & \\
\hline \multicolumn{2}{|l|}{ NSN 7540-01-280-5500 } & \multicolumn{2}{|c|}{43} & $\begin{array}{l}\text { Standard Form } 298 \text { (Rev. 2-89) } \\
\text { Prescribed by ANSI Std. 239-18 } \\
298-102\end{array}$ \\
\hline
\end{tabular}

